\title{
Mast Cell Activation in Brain Injury, Stress, and Post-traumatic Stress Disorder and Alzheimer's Disease Pathogenesis
}

\author{
Duraisamy Kempuraj ${ }^{1,2 *}$, Govindhasamy P. Selvakumar ${ }^{1,2}$, Ramasamy Thangavel ${ }^{1,2}$, \\ Mohammad E. Ahmed ${ }^{1,2}$, Smita Zaheer ${ }^{1}$, Sudhanshu P. Raikwar ${ }^{1,2}$, Shankar S. Iyer ${ }^{1,2}$, \\ Sachin M. Bhagavan ${ }^{1}$, Swathi Beladakere-Ramaswamy ${ }^{1}$ and Asgar Zaheer ${ }^{1,2 *}$ \\ ${ }^{1}$ Department of Neurology and Center for Translational Neuroscience, School of Medicine, University of Missouri, Columbia, \\ MO, United States, ${ }^{2}$ Harry S. Truman Memorial Veteran's Hospital, United States Department of Veterans Affairs, Columbia, \\ MO, United States
}

\section{OPEN ACCESS}

Edited by:

Justin John Yerbury, University of Wollongong, Australia

Reviewed by:

Mikhail Yu. Stepanichev, Institute of Higher Nervous Activity and Neurophysiology (RAS), Russia

Domenico De Berardis,

NHS England, United Kingdom

*Correspondence:

Duraisamy Kempuraj duraisamyk@health.missouri.edu Asgar Zaheer

zaheera@health.missouri.edu

Specialty section: This article was submitted to

Neurodegeneration,

a section of the journal

Frontiers in Neuroscience

Received: 10 July 2017 Accepted: 30 November 2017 Published: 12 December 2017

Citation:

Kempuraj D, Selvakumar GP, Thangavel R, Ahmed ME, Zaheer S, Raikwar SP, Iyer SS, Bhagavan SM,

Beladakere-Ramaswamy $S$ and Zaheer A (2017) Mast Cell Activation

in Brain Injury, Stress, and Post-traumatic Stress Disorder and Alzheimer's Disease Pathogenesis.

Front. Neurosci. 11:703.

doi: 10.3389/fnins.2017.00703
Mast cells are localized throughout the body and mediate allergic, immune, and inflammatory reactions. They are heterogeneous, tissue-resident, long-lived, and granulated cells. Mast cells increase their numbers in specific site in the body by proliferation, increased recruitment, increased survival, and increased rate of maturation from its progenitors. Mast cells are implicated in brain injuries, neuropsychiatric disorders, stress, neuroinflammation, and neurodegeneration. Brain mast cells are the first responders before microglia in the brain injuries since mast cells can release prestored mediators. Mast cells also can detect amyloid plaque formation during Alzheimer's disease (AD) pathogenesis. Stress conditions activate mast cells to release prestored and newly synthesized inflammatory mediators and induce increased blood-brain barrier permeability, recruitment of immune and inflammatory cells into the brain and neuroinflammation. Stress induces the release of corticotropin-releasing hormone $(\mathrm{CRH})$ from paraventricular nucleus of hypothalamus and mast cells. $\mathrm{CRH}$ activates glial cells and mast cells through $\mathrm{CRH}$ receptors and releases neuroinflammatory mediators. Stress also increases proinflammatory mediator release in the peripheral systems that can induce and augment neuroinflammation. Post-traumatic stress disorder (PTSD) is a traumatic-chronic stress related mental dysfunction. Currently there is no specific therapy to treat PTSD since its disease mechanisms are not yet clearly understood. Moreover, recent reports indicate that PTSD could induce and augment neuroinflammation and neurodegeneration in the pathogenesis of neurodegenerative diseases. Mast cells play a crucial role in the peripheral inflammation as well as in neuroinflammation due to brain injuries, stress, depression, and PTSD. Therefore, mast cells activation in brain injury, stress, and PTSD may accelerate the pathogenesis of neuroinflammatory and neurodegenerative diseases including $A D$. This review focusses on how mast cells in brain injuries, stress, and PTSD may promote the pathogenesis of AD. We suggest that inhibition of mast cells activation and brain cells associated inflammatory pathways in the brain injuries, stress, and PTSD can be explored as a new therapeutic target to delay or prevent the pathogenesis and severity of $A D$.

Keywords: Alzheimer's disease, mast cells, neurodegeneration, neuroinflammation, stress, PTSD 


\section{INTRODUCTION}

Mast cells derived from hematopoietic progenitors are multifunctional antigen presenting cells present in the tissues throughout the body (Kalesnikoff and Galli, 2008; KrystelWhittemore et al., 2015; Galli and Gaudenzio, 2017). Mast cells are involved in both health and disease conditions by releasing specific inflammatory, anti-inflammatory, and other mediators in tissues (Gurish and Austen, 2001). Mast cells are involved in immune responses, inflammation, tissue damage, and repair mechanism of the damaged tissues in peripheral organs and in the central nervous system (CNS) (Amor and Woodroofe, 2014; Skaper, 2016). Human mast cells are broadly classified into mucosal type $\left(\mathrm{MC}_{\mathrm{T}}\right)$ and connective tissue type $\left(\mathrm{MC}_{\mathrm{TC}}\right)$, based upon the type of proteases present in their cytoplasmic granules. The mucosal type of mast cells contain tryptase while the connective tissue type of mast cells contain both tryptase as well as chymase in their cytoplasmic granules (Galli, 1990; Irani and Schwartz, 1994). Brain mast cells also show similar heterogeneity (Maslinska et al., 2007). Mouse primary mast cells express various mouse mast cell proteases (MMCPs) that are different from human mast cell proteases and are classified as connective tissue mast cells (CTMC) or mucosal type mast cells (MMC) based on the expression of MMCPs (Wernersson and Pejler, 2014).

Mast cells play an important role in inflammatory pathogenesis such as anaphylactic reactions, asthma, allergy, arthritis, cardiovascular diseases, systemic mastocytosis, interstitial cystitis, psoriasis, atopic dermatitis, cancer and metastasis, endometriosis, obesity, ulcers, prostatitis, periodontitis, irritable bowel syndrome (IBS), and inflammatory bowel disease (IBD) (Sant et al., 2007; Theoharides et al., 2008, 2010, 2012a; Galli and Tsai, 2012; Kritikou et al., 2016; Suurmond et al., 2016). Additionally, we and others have shown that mast cells are also implicated in many neurological and neuroinflammatory conditions including brain injury, traumatic brain injury (TBI), stroke, Multiple sclerosis (MS), Experimental Autoimmune Encephalomyelitis (EAE), Parkinson's disease (PD), dementia, Alzheimer's disease (AD), intracerebral hemorrhage (ICH), neuropsychiatric disorders, stress conditions, sleep disorders, migraine, pain, headache, attention deficit disorder, autism, joint and muscle pain, and itching (Theoharides et al., 1995, 2005, 2016; Sayed et al., 2011; Karagkouni et al., 2013; Graziottin et al., 2014; Kempuraj et al., 2016a,b; Moretti et al., 2016; Shaik-Dasthagirisaheb and Conti, 2016). Mast cell-derived inflammatory mediators increase blood brain barrier (BBB) permeability and activate brain resident immune cells such as microglia (Ribatti, 2015). Further, mast cell mediators increase vascular permeability and increase escape and recruitment of immune and inflammatory cells at the site of injury. Optimal inflammatory responses or physiological levels of inflammatory mediators are beneficial and protect the body as they remove unwanted waste materials and repair the damaged tissues. However, excessive and chronic inflammatory responses can lead to increased inflammatory mediator levels, severe inflammation and tissue injury. Mast cells grow in numbers by increased proliferation, increased recruitment, increased survival, and accelerated maturation from their progenitors during inflammatory conditions (Bulfone-Paus et al., 2017). Mast cells are ubiquitous in the body, but they are highly concentrated in the regions where the body is directly exposed to the outer environment, and also in inflammatory and allergic tissues (Wernersson and Pejler, 2014). Thus, mast cells participate in the first line of defense from the invading pathogenic organisms and other environmental factors including pollutants (Tsai et al., 2011; Wernersson and Pejler, 2014). Further, mast cells are one of the fastest responders by releasing prestored and newly synthesized mediators among immune and inflammatory cells (Bulfone-Paus et al., 2017). Mast cells are reported as the cells that are ready to battle any time with any kind of threats to the body, since their cytoplasmic secretory granules are filled with several preformed as well as preactivated immune and inflammatory mediators including histamine, tryptase, chymase, tumor necrosis factor-alpha (TNF$\alpha$ ), serotonin, heparin, proteoglycans, and vascular endothelial growth factor (VEGF) (Beil et al., 1994; Wernersson and Pejler, 2014; Yehya and Torbey, 2017). Mast cells can generate and release reactive oxygen species (ROS) within seconds of its activation (Yehya and Torbey, 2017). Mast cells are powerful and rapid sensors of tissue injury/necrosis, infectious agents, and inflammation since they are located in the host-environment boundaries and express pattern recognition receptors and cytokines such as local alarmin, interleukin-33 (IL-33) (Martin and Martin, 2016). Mast cells detect and rapidly respond to protect from cellular injuries by detecting IL-33 released from the damaged cells (Lunderius-Andersson et al., 2012). Mast cells not only sense the cellular microenvironment in the tissues but also sense and respond to external environment such as cold, hot, humidity, pressure, allergen, and toxins (Krause et al., 2010; Engebretsen et al., 2016; Wang et al., 2016).

Mast cells are highly armed defensive system similar to our soldiers and police, protecting the body from outside and inside threats, including invasion of infectious agents, parasites, injuries, and toxins. Mast cells perform these functions rapidly by releasing prestored mediators from their granules and by synthesizing and secreting specific new chemical substances/mediators as required in acute and chronic immune responses. Mast cell committed hematopoietic progenitors from bone marrow enters into the bloodstream, gets transported into the tissues/organs, settles there and matures into specific type of mast cells depending upon the type of tissue and microenvironment, with local specific growth factors and the specific needs/threat of that particular tissue. For example, the mast cells present in the skin are connective tissue type, and mast cells present in the lung are mucosal type. Connective tissue type of mast cells can respond extensively to neuropeptides such as substance $\mathrm{P}$ and neurotensin. However, mast cells are interchangeable and thus can transform into another phenotype whenever needed in the body. Moreover, mast cells travel to another region or tissue, settle there and sense the new tissue microenvironment, and then proliferate to increase specific mast cell type based upon the requirement. Factors like infections locally and transiently increases the accumulation of mast cell progenitors and increases mast cell numbers (Zarnegar 
et al., 2017). Mast cells even migrate in to the brain from peripheral organs through $\mathrm{BBB}$ and proliferate in the brain during neuroinflammatory conditions.

Mast cell activation leads to the release of specific inflammatory mediators such as TNF- $\alpha$, IL- $1 \beta$, IL-8, IL33, chemokine (C-C motif) ligand 2 (CCL2), CCL3, CCL5, granulocyte macrophage colony-stimulating factor (GMCSF), VEGF, matrix metalloproteinase (MMPs), ROS, substance $\mathrm{P}$ (SP), stem cell factor (SCF), nerve growth factor (NGF), dopamine, transforming growth factor-beta (TGF$\beta)$, corticotrophin-releasing hormone $(\mathrm{CRH})$, neurotensin, histamine, prostaglandin D2 (PGD2), leukotrienes (LTs), proteases tryptase and chymase based upon the type of mast cells and type of stimuli in the tissues (Gilfillan et al., 2011; Wernersson and Pejler, 2014; Gaudenzio et al., 2016; Kempuraj et al., 2016b; Borriello et al., 2017). Mast cells express receptors and ligands for various immune and inflammation related pathways including CRH, SP, CD40, CD40L, SCF, cytokines, and chemokines (Kim et al., 2011; Theoharides, 2017). About $25 \%$ of rat mast cell granule content is TNF- $\alpha$ that is neurotoxic (Hendriksen et al., 2017). Inflammatory pathways in the brain with many of the above-mentioned mediators lead to neuroinflammation, which is an important process in the onset and progression of AD, PD, and MS (Zaheer et al., 2008; Chen et al., 2016; Kempuraj et al., 2016b). C-reactive protein (CRP), a marker of inflammation is implicated in mood disorders (De Berardis et al., 2006), cognitive disorders and AD (Finch and Morgan, 2007; O’bryant et al., 2016), and Post-Traumatic Stress Disorder (PTSD) (Solomon et al., 2017). A recent study showed increased blood levels of inflammatory markers IL- $1 \beta$, TNF- $\alpha$, IL-6, and IL-10 in Lewy body dementia (LBD) and increased CRP in PD dementia patients (King and Thomas, 2017). Another recent review reported possible peripheral inflammatory markers in $\mathrm{AD}$ patients (Lai et al., 2017). This report combined the results from 175 studies, analyzed 51 inflammatory markers in AD patients, and compared with control subjects. They reported increased peripheral levels of TNF- $\alpha$ converting enzyme, IL- $1 \beta$, IL-2, IL-6, IL-18, interferon-gamma (IFN- $\gamma$ ), homocysteine, high-sensitivity CRP, CCL10, epidermal growth factor (EGF), vascular cell adhesion molecule-1 (VACM-1), TNF receptor1/2, and $\alpha 1$-antichymotrypsin in $\mathrm{AD}$ patients as compared with the levels in the control subjects (Lai et al., 2017). This study suggests that $\mathrm{AD}$ pathogenesis is associated with peripheral immune and inflammatory responses, and increased IL-6 levels may be used as a biomarker to correlate with the severity of cognitive impairment in AD patients (Lai et al., 2017). Further, another inflammatory pathway marker transcription factor, nuclear factor kappa B (NF- $\mathrm{B}$ ) activity has been shown to be increased in the brains of AD patients (Hong, 2017).

Mast cells are present adjacent to the neurons and glial cells in thalamus, hypothalamus, and leptomeninges and activate them by cell-to-cell contacts as well as by releasing inflammatory and neurotoxic mediators (Theoharides et al., 2013). Mast cells located at the brain side $(>95 \%)$ of the BBB protect the brain from invading pathogens and toxic substances from the peripheral organs (Dong et al., 2014b). Mast cells play a major role in neuroinflammatory conditions including neurodegenerative diseases, stroke, MS, TBI by increasing the $\mathrm{BBB}$ permeability and activating the brain resident immune cells microglia, and T-cells (Nakae et al., 2006; Ribatti, 2015). Mast cells are implicated in the brain injuries, stress, and PTSD-induced neuroinflammation that could contribute to the pathogenesis of $\mathrm{AD}$ as shown in Figure 1. About $50 \%$ of histamine in the brain is released from the brain mast cells (Chikahisa et al., 2013). Mast cells activate glial cells and neurons through protease-activated receptor-2 (PAR-2) pathway (Yuan et al., 2010). These findings strongly suggest that mast cells are important mediators of neuroinflammation. Activation of glia is implicated in neuroinflammation-mediated neurodegeneration mechanisms (Colombo and Farina, 2016). Several studies have shown that targeting glial cells-mediated neuroinflammation is effective in the treatment of AD (McGeer and McGeer, 2015; Bolos et al., 2017; Spangenberg and Green, 2017). As mast cells are implicated in brain injury, stress, and PTSD, activation of mast cells in these conditions could increase neuroinflammation and thereby accelerate the onset and progression of $\mathrm{AD}$. Therefore, the focus of this article is to review currently available data to link the mast cell activation in stress, brain injury, and PSTD with that of pathogenesis of AD. We have searched PubMed for studies in this research area using the keywords mast cells, stress, brain injury, PTSD, and AD.

\section{BRAIN INJURY, MAST CELLS, AND INFLAMMATION}

Neuroinflammation plays central role in the CNS disorders such as $\mathrm{MS}, \mathrm{PD}, \mathrm{AD}$, brain and spinal cord injuries, stroke, depression, schizophrenia, and chronic pain (Mcgeer and Mcgeer, 2010; Anisman and Hayley, 2012; Skaper et al., 2014; Domingues et al., 2017; Mcmanus and Heneka, 2017; Sawikr et al., 2017; Schain and Kreisl, 2017). Increased levels of proinflammatory cytokines and chemokines also induce behavioral and pathological changes in the brain disorders such as $\mathrm{AD}$ and stroke (Rothwell and Strijbos, 1995; Anisman and Merali, 2003; Dantzer and Kelley, 2007). TBI is an important cause of morbidity and mortality in veterans. The initial neuroinflammatory responses after the primary brain injury is beneficial but lingering and chronic immune and neuroinflammatory responses cause additional secondary brain damage (Vink et al., 2003; Skaper et al., 2014; Corrigan et al., 2016). TBI activates glial cells, neurons and immune cells, induces neuroinflammation and neurodegeneration, axonal degeneration, elevates brain and peripheral inflammatory cytokines and chemokines, increases triggering receptor expressed on myeloid cells 2 (TREM2) expression and affects microvascular system (Elder, 2015; Elder et al., 2015). However, studies also suggest suppression of AD symptoms after TBI. Activation of immune cells and changes in the microvascular unit where mast cells are located upregulates the neuroinflammatory responses. Brain injury causes cognitive impairment, increases the accumulation of amyloid precursor protein (APP), extracellular beta amyloid $(A \beta)$ peptide and intracellular neurofibrillary tangles (NFTs) consisting of tau protein associated with inflammatory cytokine release (Johnson 


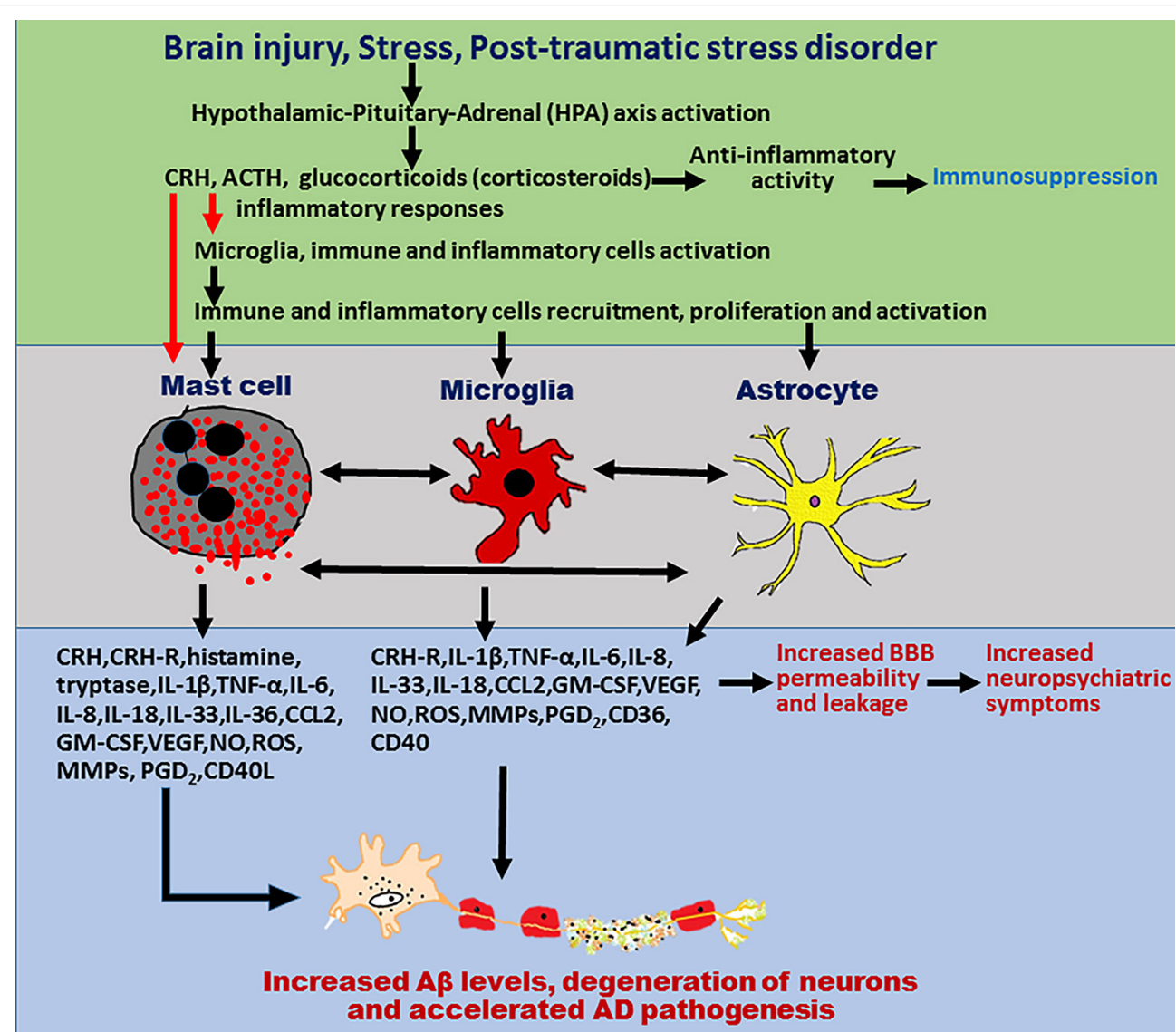

FIGURE 1 | Schematic diagram showing mast cells, brain injury, stress, and PTSD in neurodegeneration in AD pathogenesis. Mast cells-derived inflammatory mediators and direct contact of mast cells with glial cells and neurons, activates brain cells to release additional neuroinflammatory mediators that induce neurodegeneration. Stress conditions activate mast cells through $\mathrm{CRH}$ and other neuropeptides to release several neuroinflammatory mediators including cytokines, chemokines, and other neurotoxic mediators such as tryptase, histamine, IL-1 $\beta$, TNF- $\alpha$, IL-6, CCL2, IL-8, ROS, CRH, and MMPs. These inflammatory mediators in turn activate glial cells to release additional inflammatory mediators and induce neurodegeneration and neuronal death. Stress also increases BBB permeability and increases the recruitment of immune and inflammatory cells such as mast cell progenitors, mast cells, and T cells in to the brain. In addition, mast cell mediators released from the activated mast cells increase the vascular permeability, increase recruitment of immune, and inflammatory cells to the site of injury and induce neuroinflammatory reactions. These newly recruited mast cell progenitors, mast cells, and T-cells proliferate, mature, and further activate glial cells and neurons by releasing inflammatory and cytotoxic mediators leading to chronic state of neuroinflammation and neurodegeneration. PTSD also induces neuroinflammation and neurodegeneration through immune and inflammatory cells such as mast cells, T-cells, and glial cells in the brain. Mast cells, brain injury, stress conditions, and PTSD comorbidity could induce chronic neuroinflammation and neurodegeneration in neurodegenerative diseases including AD.

et al., 2012; Gupta and Sen, 2016; Kokiko-Cochran et al., 2016; Young et al., 2016). TBI is an important risk factor for neurodegenerative diseases such as dementia and AD (Barnes et al., 2014; Dams-O'connor et al., 2016; Shishido et al., 2016; Collins-Praino and Corrigan, 2017; Mendez, 2017).

Substance $\mathrm{P}$ released in TBI or under stress, activates mast cells, microglia and astrocytes, and releases additional neuroinflammatory mediators that increase BBB permeability (Corrigan et al., 2016). There is no specific and approved drug to treat TBI (Tweedie et al., 2016). One study reported that TBI with loss of consciousness influences Lewy body formation, pathogenesis of $\mathrm{PD}$ but does not result in dementia and $\mathrm{AD}$ (Crane et al., 2016). The first response after TBI is the infiltration and degranulation of mast cells in the brain (Moretti et al., 2016; Hendriksen et al., 2017). Mast cell degranulation releases cytoplasmic granule's prestored histamine and proteases. Mast cells increase $\mathrm{BBB}$ permeability and allow inflammatory cell infiltrations in the brain after cerebral ischemic brain injury (McKittrick et al., 2015). Headache associated with mild TBI is due to persistent dural mast cell degranulation and its inflammatory mediator release (Levy et al., 2016). Inhibition of mast cell activation could be used as an initial adjuvant therapy to treat hypoxia-ischemia, ischemic stroke, and ICH in new-borns and adults (Strbian et al., 2009). Increased mast cell numbers and their degranulation-derived histamine mediates ischemiainduced neuronal death in the brain (Biran et al., 2008). Mast cell number increases for days and weeks and contributes to the brain damage by releasing inflammatory mediators such as TNF and IL-9 in perinatal hypoxic-ischemia and that inhibition of mast cell activation decreased the brain damage in the immature rat 
brains (Jin et al., 2007; Ziemka-Nalecz et al., 2017). Similarly, inhibition of mast cell activation inhibits hemorrhage formation in thrombolytic ischemic stroke in rats (Strbian et al., 2007). Further, TBI has been shown to increase the number of mast cells in the injured cortical area (Lozada et al., 2005). A recent study reported that mast cells are the first responders in $\mathrm{ICH}$ and promote BBB breach, edema formation, recruit inflammatory cells, and amplify brain injury (Yehya and Torbey, 2017). These findings clearly indicate that mast cells play an important role in the neuroinflammatory responses after the brain injuries or TBI and that the enhanced neuroinflammation can predispose to the pathogenesis of AD.

\section{STRESS, MAST CELLS, AND INFLAMMATION}

Several inflammatory conditions are worsened by stress, and mast cell activation with inflammatory mediator release plays a crucial role in stress dependent inflammatory mechanism (Theoharides et al., 2004). A recent study showed chronic mild stress for 3 weeks increased the number of mast cells in the brain and disturbed sleep in mice (Chikahisa et al., 2017). Interaction between hypothalamus, pituitary, and adrenal gland is an important stress response in neuropsychiatric conditions and depression (Anisman and Merali, 2003). Stress activates hypothalamo-pituitary-adrenal (HPA) axis within seconds and increases the release of $\mathrm{CRH}$ and arginine vasopressin (AVP) from the paraventricular nucleus (PVN) of the hypothalamus in the brain, enhances mast cell activation, vascular permeability, and the expression of CRH receptors (Lytinas et al., 2003; Claes, 2004; Theoharides et al., 2004). Proinflammatory cytokines also activates HPA axis (Hayley, 2011). Furthermore, stress causes $\mathrm{CRH}$ release from hypothalamus into the pituitary gland and releases adrenocorticotropic hormone (ACTH) from the pituitary gland. ACTH acts on adrenal cortex to release glucocorticoids, which in turn inhibit the release of CRH and $\mathrm{ACTH}$ in a negative feedback mechanism. CRH and ACTH directly activate microglia to release neuroinflammatory mediators (Karagkouni et al., 2013). Psychological and environmental stress conditions induces the release of CRH. $\mathrm{CRH}$ also called as corticotropin-releasing factor (CRF), is a 41 amino acid peptide released from hypothalamic neurons as well as from the activated mast cells (Kato et al., 2013). VEGF, an angiogenic cytokine that plays an important role in inflammation, is also elevated in PTSD patients (De Kloet et al., 2008; Pervanidou and Chrousos, 2012). We have shown that stress, CRH, mast cell activation, and VEGF play a crucial role in stress-induced exacerbation of inflammation (Cao et al., 2006a). Further, peripheral derived CRH also augments stress mediated effects (Nozu et al., 2017). We have previously shown that mast cell activation and $\mathrm{CRH}$ release under stress conditions increases $\mathrm{BBB}$ permeability, and tumor metastases into the brain (Esposito et al., 2001, 2003; Theoharides et al., 2008; Rozniecki et al., 2010). Further, stress induced vascular permeability, an important event in inflammation is reduced in mast cell deficient mice (Kandere-Grzybowska et al., 2003a).
Acute stress is reported to accelerate the pathogenesis of neuroinflammatory and autoimmune disease EAE in mice (Chandler et al., 2002).

$\mathrm{CRH}$ activates mast cells to release various neuroinflammatory and neurotoxic mediators that leads to a breach of $\mathrm{BBB}$ and activates glial cells to release more inflammatory mediators, thereby contributing to the chronic neuroinflammation in the brain (Cao et al., 2006b; Theoharides et al., 2013). Acute stress increases $\mathrm{BBB}$ permeability through brain mast cell activation and CRH release (Theoharides and Konstantinidou, 2007). Microglia express $\mathrm{CRH}$ receptors, and activation of microglia by $\mathrm{CRH}$ from brain cells cause the release of neurotoxic inflammatory mediators in mental disorders (Kritas et al., 2014a). Activation of rat microglia by $\mathrm{CRH}$ through CRHR1-induces microglial proliferation and release of TNF- $\alpha$ and activation of mitogen-activated protein kinase (MAPKs) (Kato et al., 2013). $\mathrm{CRH}$ also increases microglial expression of IL-18 which is implicated in stress, depression, and PTSD conditions (Kato et al., 2013). A recent report using mast cell and CRHR1 deficient mice reported that CRHR1 mediates stress-induced mast cell degranulation (Ayyadurai et al., 2017). Inflammatory mediators released from microglia induce neuronal destruction in neurodegenerative diseases (Kritas et al., 2014a). Several stressors increase aging-like process and activate microglia toward proinflammatory phenotype causing destruction of neurons (Brown and Vilalta, 2015; Calcia et al., 2016; Niraula et al., 2016). Stress conditions clearly activate microglia in the brain (Delpech et al., 2015). Microglial activation plays an important role in the pathogenesis of neurodegenerative diseases (Perry et al., 2010; Perry and Holmes, 2014; Perry, 2016). Microglia and mast cells which develop from hematopoietic progenitors are reported as two tracks to the road to neuroinflammation (Skaper et al., 2012).

We have previously shown that human mast cells synthesize and secrete $\mathrm{CRH}$ and express functional $\mathrm{CRH}$ receptors (CRHR1 and CRH-R2) (Kempuraj et al., 2004; Cao et al., 2005; Papadopoulou et al., 2005). CRH released from mast cell acts in an autocrine as well as paracrine manner to activate mast cells and glial cells in the CNS in stress and neuroinflammatory conditions (Karagkouni et al., 2013; Kritas et al., 2014b). Social stressful experience is associated with psychiatric disorders with enhanced inflammatory responses (Finnell and Wood, 2016). The level of stress-related pathology varies from one person to another, due to the differences in the levels of immune and inflammatory response specifically mast cell response to various stressors and activation signals (Forsythe and Ennis, 2000; Finnell and Wood, 2016; Gaudenzio et al., 2016). Patients with depression exhibit elevated proinflammatory cytokine levels in the plasma and cerebrospinal fluid (CSF) (Finnell and Wood, 2016). Microglial activation is increased in the brains of depressed patients and this increase is correlated with the severity of the depression (Setiawan et al., 2015). Social stress and depression can affect anyone at any age, gender, ethnicity, and socio-economic background (Finnell and Wood, 2016). Previous reports suggest that stress, depression and PSTD are more prevalent in female than male patients (Breslau, 2002; Finnell and Wood, 2016; Mendoza et al., 2016). 
Psychological and environmental stress induces or worsens anxiety and depression, activates neurons, microglia, and induces neuronal dystrophy (Wohleb, 2016; Mondelli et al., 2017). Stress due to cold worsens neuroinflammation, induces oxidative stress, neuronal autophagy, and enhances immune responses ( $\mathrm{Qu}$ et al., 2017; Theoharides, 2017). Mast cells are linked with inflammatory pathways leading to chronic depression in mastocytosis patients (Georgin-Lavialle et al., 2016). Mastocytosis patients also show increased oxidative stress markers of inflammation (Gangemi et al., 2015). Stress worsens several conditions such as migraines, by activating mast cells to release inflammatory mediators (Theoharides et al., 1995; Castellani et al., 2010). Stress is undoubtedly linked to the severity of neurodegenerative disorders. Work-related stress such as job security, job environment and lack of job satisfaction increases the risk for vascular dementia and $\mathrm{AD}$ (Andel et al., 2012). CRH released in stressful conditions is protective at a lower concentration, but is harmful at higher concentrations and exacerbates AD progression (Pardon, 2011).

Chronic stress can accelerate $\mathrm{AD}$ pathogenesis in human and animal models through increases in inflammatory responses, $\mathrm{A} \beta$ accumulation, tau hyperphosphorylation, oxidative stress, mitochondrial impairment, and glucose metabolism (Machado et al., 2014). Stress in early-life increases the risk of cognitive disorders in the aged mouse model of $\mathrm{AD}$ (Hoeijmakers et al., 2017). Early life chronic stress in transgenic APP/PS1 $\mathrm{AD}$ mice from postnatal day 2 to 9 has been shown to increase $\mathrm{A} \beta$ pathology, neuroinflammatory mediators, and neuroinflammatory responses in 4 and 10 months-old mice as compared to age matched-wild type mice. Additionally, early life stress induced both immediate as well as late effects; increased inflammatory responses, CD68 expression and neuroinflammatory levels in the hippocampus in an age-dependent manner in $\mathrm{AD}$ mouse model (Hoeijmakers et al., 2017). Adolescent stage stress exposure affect brain development, causes depression and brain dysfunctions in the adulthood (Eiland and Romeo, 2013). Chronic stress conditions create a vicious cycle of increased microglial dysfunction associated decreased clearance, and increased $A \beta$ accumulation exacerbating neuroinflammation and neurodegeneration. The mechanism that chronic stress contributes to microglia-mediated neuroinflammation and cognitive impairments in $\mathrm{AD}$ is not yet clearly known and that therapeutic interventions to stressmediated effects could delay the onset, progression, and severity of AD (Piirainen et al., 2017). CD33, CD36, and TREM2 are implicated in stress and $\mathrm{AD}$ progression and that stressful conditions exacerbate $A \beta$ pathology in the animal models of AD (Piirainen et al., 2017). Increased cortisol levels and HPA axis dysregulation have been implicated in stress conditions and $\mathrm{AD}$. Chronic stress has been shown to release more $\mathrm{A} \beta$, trigger and worsen AD severity (Morgese et al., 2017). A recent study reported that $\mathrm{Tg}-\mathrm{AD}$ mouse model treated with CRHR1 antagonist R121919 showed decreased stress mediated oxidative damage, prevented the onset of cognitive impairment and dendritic loss and reduced $A \beta$ deposition in the brain (Zhang and Rissman, 2017). They report that stress hormones activate neuronal oxidative stress, which increases the release of additional stress hormones and cause neuronal damage in the hippocampus in $\mathrm{AD}$ brains. The authors further suggest that suppression of stress pathways might be an effective therapy for AD (Zhang and Rissman, 2017).

Chronic stress and short-term modern life-like stress upregulates $\mathrm{AD}$ severity in $3 \mathrm{xTg}-\mathrm{AD}$ mice, an animal model of AD (Baglietto-Vargas et al., 2015). They report that combined emotional and physical stress lasting for $5 \mathrm{~h}$ significantly impaired memory in these $\mathrm{AD}$ mice as compared to wild type mice. Further, these stress conditions reduced the number of dendritic spines and increased $\mathrm{A} \beta$ levels in these $3 \mathrm{xTg}-\mathrm{AD}$ mice (Baglietto-Vargas et al., 2015). Neurotensin, a neuropeptide along with $\mathrm{CRH}$ augments mast cell activation and release of excessive inflammatory mediators in stressful situations (Alysandratos et al., 2012). Immobilization (restrain) stress induces HPA axis and activates intracranial mast cells to release tryptase, a mast cell specific inflammatory protease within $30 \mathrm{~min}$ in rats as shown by light and electron microscopy. Pretreatment of these animals with anti-CRH before stress inhibited intracranial mast cell activation (Theoharides et al., 1995). Chronic psychological stress is a risk factor for dementia and $\mathrm{AD}$ by inducing microglial proinflammatory status (Piirainen et al., 2017). These reports strongly indicate that mast cells play a crucial role in stress responses associated with inflammation that may predispose to $\mathrm{AD}$ pathogenesis in high-risk groups.

\section{PTSD, MAST CELLS, AND INFLAMMATION}

PTSD is a traumatic stress-related emotional disorder associated with chronic low-grade inflammation (Zass et al., 2017). PTSD causes behavioral impairments as well as immunological disorders (Banks et al., 1995). PTSD is an important concern in war veterans and the combat soldiers at the war regions, and they are at a high risk of developing this disorder. U.S deployed over 2.5 million service members to Iraq since 2001 and about $15 \%$ of them developed PTSD after their combat experience. PTSD also affects civilians following trauma or loss of family members (Dursa et al., 2014; Wang and Young, 2016). PTSD patients show chronic stress responses along with low-grade inflammatory reactions in the body (Zass et al., 2017). Most of the people with trauma did not develop PTSD, but only some people develop PTSD. This is because of the other factors such as stress and socio economic factors that may be considered as important risk factors for the pathogenesis of PTSD (Digangi et al., 2013). However, the exact mechanism of the pathogenesis of PTSD is not yet clearly known and therefore no effective treatment options are currently available. Recent studies have shown that immune disorders with excessive inflammatory reactions are present in PTSD patients. Additionally, mast cells, the soldiers of our body's (innate and acquired) defense system are also dysregulated in the combat soldiers. Therefore, it is necessary to urgently understand the pathogenesis of PTSD to take care of our affected defense personnel and to prevent the pathogenesis of PTSD in general. Several reports strongly suggest elevated neuroinflammation in depressed patients and in chronic stress conditions (Zass et al., 2017). Also, behavioral disorders and neuroinflammation are 
closely linked with peripheral inflammation in social stress model of PTSD (Muhie et al., 2017).

It has been suggested that PTSD, depression, and stress induces low-grade chronic inflammation that could lead to neurodegenerative diseases. Chronic stress, depression, and PTSD in war zone soldiers may be responsible for the increased inflammatory reactions in the active duty American soldiers (Groer et al., 2015). Mast cells could play an important role in the battlefield soldiers due to stress, mood, fearful behavioral activities, and change in the outer environmental conditions. Mast cell numbers are high in the skin, gastrointestinal tract, and respiratory tract through which the body is directly exposed to outer environment. Changes in the outer environmental conditions such as outside temperature (cold or hot), light and darkness, odors, and toxic substances in the air affects/activates mast cells in the barrier regions and increases their numbers to respond (Nakamura et al., 2017). For example, outer environmental cold and low humidity conditions activates skin mast cells, allergen/toxins in the air activates nasal, airways, and ocular regions mast cells and causes acute or chronic allergic and inflammatory reactions (Petra et al., 2014). Additionally, human behavioral and emotional conditions also influences mast cell activations and their numbers in specific regions of the body including in the brain areas (Nautiyal et al., 2008).

A previous report suggests that PTSD-like trauma with high $\mathrm{CRH}$ level induces dementia and AD pathogenesis (Justice et al., 2015). Studies have linked PTSD with inflammation related diseases, elevated inflammatory responses, and accelerated aging process (Tsai et al., 2011; Wolf and Schnurr, 2016; Lindqvist et al., 2017). Peripheral inflammatory markers and total inflammatory scores are shown to be higher in combat experienced veterans with PTSD, as compared to veterans without PTSD (Lindqvist et al., 2017). It is interesting to note that comorbidity of TBI and PTSD shows augmented inflammation, associated with elevated IL- 6 and TNF- $\alpha$ levels, and this increase correlates with the severity of PTSD symptoms (Devoto et al., 2016). Similarly, studies have also shown elevated levels of IL-6, IL-1 $\beta$, TNF- $\alpha$, and IFN- $\gamma$ in PTSD patients (Cohen et al., 2011; Passos et al., 2015). These cytokines can bind to receptors in the glial cells and phosphorylate MAPKs, which leads to the activation of nuclear factor-kappa B (NF-кB) and release of inflammatory mediators. Supporting this notion, we have previously reported that IL1 activates mast cells to release IL- 6 through the activation of p38 MAPK (Kandere-Grzybowska et al., 2003b, 2006; Castellani et al., 2009). A recent report indicates that chronic stress and anxiety increases the rate of PTSD (Zass et al., 2017). Systemic inflammation marker, CRP is increased in depression as well as in PTSD patients, indicating that PTSD patients show enhanced inflammatory responses (Powers et al., 2016; Miller et al., 2017; Solomon et al., 2017). Thus, it has been suggested that certain inflammatory markers can be used as biomarkers for PTSD (Cohen et al., 2011).

A study conducted on Iraq and Afghanistan deployed USveterans under the age of 55 that were associated with PSTD and endocrine and immune abnormalities reported increased risk for developing autoimmune diseases such as MS, rheumatoid arthritis, thyroiditis, lupus erythematosus, and inflammatory bowel disease (IBD) (O'donovan et al., 2015). Hence, there is a clear evidence that PTSD is an important risk factor for several autoimmune and mast cell associated diseases. Cytokines and chemokines including TNF- $\alpha$, IL- 6 , and IL- $1 \beta$ cross BBB and induce neuroinflammation directly, and also by activating inflammatory, glial, and neuronal cells in the brain (Banks et al., 1995). Further, inflammatory cytokines released from activated glial cells, and inflammatory cells contribute to the chronic pain in PSTD (Lerman et al., 2016). Additionally, mast cell-derived inflammatory mediators including SP strongly contribute to the pain in PTSD patients. Stress increases the release of $\mathrm{CRH}$ and this $\mathrm{CRH}$ activates $\mathrm{HPA}$ axis in stress responses in PTSD patients with depression (Mendoza et al., 2016). This elevated CRH increases the vascular permeability and activates glial cells and inflammatory cells such as mast cells to release additional inflammatory mediators (Mendoza et al., 2016). Moreover, mast cells also contribute to the increased level of CRH in the brain, as mast cells are target as well as source for $\mathrm{CRH}$ as we reported previously (Kandere-Grzybowska et al., 2003b; Kempuraj et al., 2004). During the stress conditions, elevated inflammatory mediators cross BBB and induce/augment neuroinflammation that accelerates the pathogenesis of $\mathrm{AD}$. These findings indicate that stress accompanied with chronic inflammation in PTSD could lead to neurodegeneration in diseases such as AD. Moreover, PTSD is a known risk factor for dementia in the veterans and also in civilians (Flatt et al., 2017). However, mast cells are clearly involved in peripheral and CNS inflammation and in various stress conditions and trauma, but the exact role of mast cells is not yet studied in PTSD patients. Moreover, mast cells could increase both acute and chronic inflammatory reactions in stress, brain injuries, and PTSD and could contribute to the development and progression of $\mathrm{AD}$ (Figure 1).

\section{MAST CELLS, NEUROINFLAMMATION, AND AD}

$\mathrm{AD}$ is the most prevalent chronic progressive neurodegenerative disease associated with dementia, neuroinflammation, and neurodegeneration (McGeer et al., 2016). AD is considered as an inflammatory disease involving immune components in the brain (Heneka et al., 2015; McGeer and McGeer, 2015; Bolos et al., 2017). AD pathogenesis begins even 10 years before the clinical symptoms are identified in $\mathrm{AD}$ patients (McGeer et al., 2016). There are no effective drugs to treat neurodegeneration in $\mathrm{AD}$ since the disease mechanisms are not yet clearly understood. Anti-inflammatory and antidepressants can reduce neuroinflammation in dementia and AD (Hashioka et al., 2009; McGeer et al., 2016). Inflammatory mediators induce neuroinflammation, synaptic dysfunction, hyperphosphorylated tau generation, $\mathrm{A} \beta$ production, and neurodegeneration in the brain (Mohammadzadeh Honarvar et al., 2017). Anti-inflammatory drugs are neuroprotective and suppress disease progression by reducing $A \beta$ generation and its accumulation, inflammatory mediator release with improvement of cognitive functions (Budni et al., 2016; 
McGeer et al., 2016; Mohammadzadeh Honarvar et al., 2017). $\mathrm{A} \beta$ pathology and normal aging processes are associated with activation of immune as well as inflammatory cells in the brain. Neuroinflammation and neurodegeneration are vicious cyclic processes in neurodegenerative diseases and in normal aging processes. Available current research evidence indicates that neuroinflammation clearly contributes to the neurodegeneration in several neurodegenerative diseases (Glass et al., 2010; Kempuraj et al., 2016b, 2017b). However, the exact mechanism of neuroinflammation is not yet clearly understood. Neuroinflammation is a complex mechanism involving different immune and inflammatory cells and different inflammatory mediators in $\mathrm{AD}$ pathogenesis, brain injuries, and stress conditions. The currently available anti-inflammatory drugs are not affecting all or the key inflammatory mediators or genes in these conditions. Moreover, these diseases and disorders are multifactorial and the anti-inflammatory drugs or antidepressants need to affect specific inflammatory pathways and inflammatory mediators in specific diseases for its maximal beneficial effects. BBB is one of the main problems in delivering the drugs that acts on neuroinflammation. These drugs should also be effective in stress-mediated hormonal disorders in addition to neuroinflammation (Galecki et al., 2018). CRHantagonists could be therapeutic agents in stress-related CNS and peripheral inflammatory disorders (Nezi et al., 2000). More importantly, anti-inflammatory and other currently available drugs do not completely stop the onset or progression of the disease and do not induce regeneration of neurons and its network connections in the affected brain regions. Continued and extensive research in this field is essential to achieve this goal in the future.

Various conditions including stress conditions induce/augment neuroinflammation and $\mathrm{AD}$ pathogenesis. Mast cell activation causes either neuroprotection or neuroinflammation based upon the level and number of cells activated (Mukai et al., 2016). Excessive and chronic activation of mast cells lead to neuroinflammation and neurodegeneration. Though mast cells are implicated in neuroinflammatory diseases such as MS, EAE and PD, the role of mast cells in AD pathogenesis is still elusive. Several lines of evidence indicates that mast cell activation could accelerate $\mathrm{AD}$ pathogenesis in high-risk group patients with brain injury and trauma, stress conditions, and PTSD. Since mast cells play important role in inflammation, neuroinflammation, stress, and psychiatric disorders, it is important to study its role in the pathogenesis of PTSD-associated neurodegenerative diseases such as AD. Several recent studies show that proinflammatory cytokines and mast cell-derived inflammatory mediators are implicated in neuroinflammation and neurodegeneration in the CNS (Purcell and Atterwill, 1995; Yuan et al., 2010; Banuelos-Cabrera et al., 2014; Dong et al., 2014b; Becher et al., 2017; Spangenberg and Green, 2017). Brain proinflammatory protein glia maturation factor (GMF) which was discovered in our laboratory is involved in the pathogenesis of $\mathrm{AD}$ and MS/EAE (Lim et al., 1989; Zaheer et al., 2007, 2011a,b; Stolmeier et al., 2013; Thangavel et al., 2013 , 2017). We have recently reported that GMF regulates neuroinflammation through NLRP3 inflammasome in AD brain
(Ahmed et al., 2017). Further, we have shown that mast cells also express GMF and suggest that GMF in mast cells may also play an important role in the pathogenesis of neurodegenerative diseases including AD (Kempuraj et al., 2015). Additionally, we have also shown that GMF activates mouse and human mast cells to release mast cell specific proteases and other neuroinflammatory mediators that are implicated in neuroinflammation and neurodegeneration in PD and AD (Kempuraj et al., 2015, 2017a). We have previously reported enhanced expression of IL-33 and GMF at the vicinity of APs and NFTs in human AD brain (Xiong et al., 2014). Further, we demonstrated that incubation of mouse astrocytes with $A \beta$ 1-42 in vitro increased the expression of IL-33 indicating IL-33 is implicated in AD (Xiong et al., 2014).

$\mathrm{SP}$ is involved in the neurodegenerative diseases. We have shown that IL-33 increases SP-mediated release of inflammatory mediator from mast cells (Theoharides et al., 2010). These results suggest that IL-33 released from astrocytes could activate microglia and mast cells in the brain, as IL-33 is a strong activator of mast cells (Hudson et al., 2008; Castellani et al., 2009; Yasuoka et al., 2011). However, another study showed that injection of IL33 led to improved memory deficit in APP/PS1 AD mice model (Fu et al., 2016). This suggests that IL-33 could act differently depending upon the environment and concentration. Mast cells are the first immune responding cells in the brain before other cells in certain conditions (Dong et al., 2014b; Hendriksen et al., 2017). Mast cells are suggested as one of the first brain cells that detect and respond early to $A \beta$ formation in the pathogenesis of AD (Harcha et al., 2015; Hendriksen et al., 2017). These studies suggest that mast cells specifically identify the ongoing process in the formation of $\mathrm{A} \beta$ in the pathogenesis of $\mathrm{AD}$. The association of mast cells and $\mathrm{AD}$ is reported in mastocytosis (increased mast cells in the body) patients. Expression of $A \beta$ peptide, major component of amyloid plaques (APs) in $\mathrm{AD}$ and tau-protein has been reported in the skin mast cells of mastocytosis patients (Kvetnoi et al., 2003). A $\beta$ peptide has been reported to activate mast cells to release inflammatory mediators that are implicated in the pathogenesis of AD (Niederhoffer et al., 2009). Increased levels of ROS in AD could activate mast cells to release inflammatory mediators (Chelombitko et al., 2016). Several mast cell-derived inflammatory mediators are reported to be involved in the AD pathogenesis and its level of severity (Shaik-Dasthagirisaheb and Conti, 2016). Mast cells, in fact are similar to neurons with regard to synthesis and secretion of neurotrophic factors, responsiveness to neuropeptides and monoaminergic content such as dopamine (Purcell and Atterwill, 1995).

Mast cells are mostly located in choroid plexus, leptomeninges, and brain parenchyma and form a unit in the neurovascular structure in the CNS (Banuelos-Cabrera et al., 2014). Mast cells migrate and accumulate in the specific region of the brain. Many factors such as cytokines/chemokines, eicosanoids, VEGF, and fibroblast growth factor (FGF), platelet derived endothelial cell growth factor influence the movement, activation and degranulation of mouse mast cells (Gruber et al., 1995). Several neurotrophic factors induce mast cells to release histamine (Purcell et al., 1996) that activates microglia through histamine receptors $\mathrm{H} 1$ and $\mathrm{H} 4$ to release neurotoxic 
mediators such as IL- $1 \beta$, TNF- $\alpha$, IL-6, and nitric oxide (NO) (Dong et al., 2014a). These proinflammatory mediators directly induce neuronal death in the brain. Inflammatory cytokines such as IL-1 $\beta$ are known to phosphorylate tau (Collins-Praino and Corrigan, 2017; Domingues et al., 2017) and induce neurodegeneration (Rothwell and Luheshi, 2000). A $\beta$-peptides are normal products of the metabolism that induce localized as well as general inflammatory responses [10]. Elevated intracellular concentration of calcium induces $A \beta$ aggregation in the $\mathrm{AD}$ brain and activates human mast cells to release inflammatory mediators (Kempuraj et al., 2005; Theoharides et al., 2010; Koran et al., 2014). The number of mast cells in the normal brain is less; however, the number increases in the affected regions in $\mathrm{AD}$ brains (Banuelos-Cabrera et al., 2014).

Mitochondrial uncoupling proteins (UCPs) are implicated in neurodegenerative diseases. We have recently reported downregulation of the expression of UCPs 2 and 4 in the parahippocampal gyrus of $\mathrm{AD}$ brains where GMF expression is also increased (Thangavel et al., 2017). We have also previously shown that mast cells express UCP2 and UCP 4 (Tagen et al., 2009; Kempuraj et al., 2016a) and GMF (Kempuraj et al., 2015). Further, we showed that deficiency of UCP2 in mouse mast cells decreased the release of inflammatory mediators such as IL-6, PGD 2 , and histamine with inhibition of MAPKs activation (Tagen et al., 2009). Another study has shown that UCP2 deficient microglia released more NO and IL-6 when stimulated with lipopolysaccharide (De Simone et al., 2015). These findings show that mast cell UCPs could be implicated in the pathogenesis of $\mathrm{AD}$.

Although recent reports suggest that mast cells and CRH are crucial in the pathogenesis of $\mathrm{AD}$, there are some controversies regarding this hypothesis (Rehman, 2002; Pardon, 2011). The concentration of $\mathrm{CRH}$ has been reported to be higher in the regions prone to develop $\mathrm{AD}$ related pathological changes (Pedersen et al., 2001). Mast cell activation induces postoperative cognitive dysfunction (POCD) after surgical procedure-mediated neuroinflammation (Li et al., 2017). Chymotrypsin-like protease was reported in the meningeal and intracortical perivasculature where there is high $A \beta$ accumulation in rat $\mathrm{AD}$ brains. This chymotrypsin-like protease has been suggested to influence aggregation of A $\beta$ deposition (Nelson et al., 1993). Mast cells express $\operatorname{IgE}$ receptor (FceRI), release histamine and play

\section{REFERENCES}

Ahmed, M. E., Iyer, S., Thangavel, R., Kempuraj, D., Selvakumar, G. P., Raikwar, S. P., et al. (2017). Co-Localization of glia maturation factor with NLRP3 inflammasome and autophagosome markers in human Alzheimer's disease brain. J. Alzheimers Dis. 60, 1143-1160. doi: 10.3233/JAD-170634

Alysandratos, K. D., Asadi, S., Angelidou, A., Zhang, B., Sismanopoulos, N., Yang, H., et al. (2012). Neurotensin and CRH interactions augment human mast cell activation. PLoS ONE 7:e48934. doi: 10.1371/journal.pone.0048934

Amor, S., and Woodroofe, M. N. (2014). Innate and adaptive immune responses in neurodegeneration and repair. Immunology 141, 287-291. doi: $10.1111 / \mathrm{imm} .12134$ important role in mediating various allergic reactions (Frieri et al., 2015; Arthur and Bradding, 2016). Presence of allergic diseases such as asthma in which mast cells are increased as well as heavily activated are strongly linked to phosphorylation of tau, dementia, and AD (Chen et al., 2014; Bolos et al., 2017; Galli, 2017). We have recently reported that mast cell activation in several inflammatory conditions in the periphery could increase neuroinflammation and neurodegeneration (Kempuraj et al., 2017b). These findings show that mast cells are implicated in the pathogenesis of $\mathrm{AD}$. Moreover, it has been shown that mast cells play important role in stress induced severity of asthma (Theoharides et al., 2012b). Stress conditions exacerbate asthma severity by increasing the number of mast cells as well as increased number of activated mast cells.

\section{CONCLUSIONS AND PERSPECTIVES}

Mast cell activation is implicated in neuroinflammation, brain injuries, and various stress conditions. We suggest that mast cells participate in the pathogenesis of $\mathrm{AD}$, and this process could be accelerated and worsened in brain injury, stress, and PTSD comorbidity. Inhibition of mast cell-associated inflammatory pathways in brain injury, stress, and PTSD could be explored as a new therapeutic target to inhibit or prevent the pathogenesis and potentially delay the onset of AD. Though the evidence is currently limited, investigating the role of mast cell activation in brain injuries, stress, and PTSD comorbidity in the onset and progression of $\mathrm{AD}$ is an important emerging new area to understand and to effectively treat neuroinflammatory disorders including $\mathrm{AD}$.

\section{AUTHOR CONTRIBUTIONS}

DK: Conceptualization, wrote, and edited the manuscript; AZ: Funding acquisition, provided resources and edited the manuscript; GS, RT, MA, SZ, SR, SI, SB, and SB-R: Edited the manuscript.

\section{FUNDING}

This work was supported by the National Institutes of Health Grants \# AG048205, \# NS073670, and Veteran Affairs Merit Award \# I01BX002477 to AZ. 
and stress-induced pathophysiology. J. Leukoc. Biol. 102, 1299-1312. doi: 10.1189/jlb.2HI0317-088RR

Baglietto-Vargas, D., Chen, Y., Suh, D., Ager, R. R., Rodriguez-Ortiz, C. J., Medeiros, R., et al. (2015). Short-term modern life-like stress exacerbates Abeta-pathology and synapse loss in 3xTg-AD mice. J. Neurochem. 134, 915-926. doi: 10.1111/jnc.13195

Banks, W. A., Kastin, A. J., and Broadwell, R. D. (1995). Passage of cytokines across the blood-brain barrier. Neuroimmunomodulation 2, 241-248. doi: $10.1159 / 000097202$

Banuelos-Cabrera, I., Valle-Dorado, M. G., Aldana, B. I., Orozco-Suarez, S. A., and Rocha, L. (2014). Role of histaminergic system in blood-brain barrier dysfunction associated with neurological disorders. Arch. Med. Res. 45, 677-686. doi: 10.1016/j.arcmed.2014.11.010

Barnes, D. E., Kaup, A., Kirby, K. A., Byers, A. L., Diaz-Arrastia, R., and Yaffe, K. (2014). Traumatic brain injury and risk of dementia in older veterans. Neurology 83, 312-319. doi: 10.1212/WNL.0000000000000616

Becher, B., Spath, S., and Goverman, J. (2017). Cytokine networks in neuroinflammation. Nat. Rev. Immunol. 17, 49-59. doi: 10.1038/nri.2016.123

Beil, W. J., Login, G. R., Galli, S. J., and Dvorak, A. M. (1994). Ultrastructural immunogold localization of tumor necrosis factor-alpha to the cytoplasmic granules of rat peritoneal mast cells with rapid microwave fixation. J. Allergy Clin. Immunol. 94, 531-536. doi: 10.1016/0091-6749(94)90210-0

Biran, V., Cochois, V., Karroubi, A., Arrang, J. M., Charriaut-Marlangue, C., and Heron, A. (2008). Stroke induces histamine accumulation and mast cell degranulation in the neonatal rat brain. Brain Pathol. 18, 1-9. doi: 10.1111/j.1750-3639.2007.00092.x

Bolos, M., Perea, J. R., and Avila, J. (2017). Alzheimer's disease as an inflammatory disease. Biomol. Concepts 8, 37-43. doi: 10.1515/bmc-2016-0029

Borriello, F., Iannone, R., and Marone, G. (2017). Histamine release from mast cells and basophils. Handb. Exp. Pharmacol. 241, 121-139. doi: 10.1007/164_2017_18

Breslau, N. (2002). Gender differences in trauma and posttraumatic stress disorder. J. Gend. Specif. Med. 5, 34-40.

Brown, G. C., and Vilalta, A. (2015). How microglia kill neurons. Brain Res. 1628, 288-297. doi: 10.1016/j.brainres.2015.08.031

Budni, J., Garcez, M. L., De Medeiros, J., Cassaro, E., BellettiniSantos, T., Mina, F., et al. (2016). The anti-inflammatory role of minocycline in Alzheimer s disease. Curr. Alzheimer Res. 13, 1319-1329. doi: 10.2174/1567205013666160819124206

Bulfone-Paus, S., Nilsson, G., Draber, P., Blank, U., and Levi-Schaffer, F. (2017). Positive and negative signals in mast cell activation. Trends Immunol. 38, 657-667. doi: 10.1016/j.it.2017.01.008

Calcia, M. A., Bonsall, D. R., Bloomfield, P. S., Selvaraj, S., Barichello, T., and Howes, O. D. (2016). Stress and neuroinflammation: a systematic review of the effects of stress on microglia and the implications for mental illness. Psychopharmacology 233, 1637-1650. doi: 10.1007/s00213-016-4218-9

Cao, J., Boucher, W., Kempuraj, D., Donelan, J. M., and Theoharides, T. C. (2006a). Acute stress and intravesical corticotropin-releasing hormone induces mast cell dependent vascular endothelial growth factor release from mouse bladder explants. J. Urol. 176, 1208-1213. doi: 10.1016/j.juro.2006.04.026

Cao, J., Cetrulo, C. L., and Theoharides, T. C. (2006b). Corticotropin-releasing hormone induces vascular endothelial growth factor release from human mast cells via the cAMP/protein kinase A/p38 mitogen-activated protein kinase pathway. Mol. Pharmacol. 69, 998-1006. doi: 10.1124/mol.105.019539

Cao, J., Papadopoulou, N., Kempuraj, D., Boucher, W. S., Sugimoto, K., Cetrulo, C. L., et al. (2005). Human mast cells express corticotropin-releasing hormone (CRH) receptors and CRH leads to selective secretion of vascular endothelial growth factor. J. Immunol. 174, 7665-7675. doi: 10.4049/jimmunol.174.12.7665

Castellani, M. L., Galzio, R. J., Felaco, P., Tripodi, D., Toniato, E., De Lutiis, M. A., et al. (2010). VEGF, substance $P$ and stress, new aspects: a revisited study. J. Biol. Regul. Homeost. Agents 24, 229-237.

Castellani, M. L., Kempuraj, D., Salini, V., Vecchiet, J., Tete, S., Ciampoli, C., et al. (2009). The latest interleukin: IL-33 the novel IL-1-family member is a potent mast cell activator. J. Biol. Regul. Homeost. Agents 23, 11-14.

Chandler, N., Jacobson, S., Esposito, P., Connolly, R., and Theoharides, T. C. (2002). Acute stress shortens the time to onset of experimental allergic encephalomyelitis in SJL/J mice. Brain Behav. Immun. 16, 757-763. doi: 10.1016/S0889-1591(02)00028-4
Chelombitko, M. A., Fedorov, A. V., Ilyinskaya, O. P., Zinovkin, R. A., and Chernyak, B. V. (2016). Role of reactive oxygen species in mast cell degranulation. Biochem. Mosc. 81, 1564-1577. doi: $10.1134 /$ S000629791612018X

Chen, M. H., Li, C. T., Tsai, C. F., Lin, W. C., Chang, W. H., Chen, T. J., et al. (2014). Risk of dementia among patients with asthma: a nationwide longitudinal study. J. Am. Med. Dir. Assoc. 15, 763-767. doi: 10.1016/j.jamda.2014.06.003

Chen, W. W., Zhang, X., and Huang, W. J. (2016). Role of neuroinflammation in neurodegenerative diseases (Review). Mol. Med. Rep. 13, 3391-3396. doi: $10.3892 / \mathrm{mmr} .2016 .4948$

Chikahisa, S., Harada, S., Shimizu, N., Shiuchi, T., Otsuka, A., Nishino, S., et al. (2017). Mast cell involvement in glucose tolerance impairment caused by chronic mild stress with sleep disturbance. Sci. Rep. 7:13640. doi: 10.1038/s41598-017-14162-w

Chikahisa, S., Kodama, T., Soya, A., Sagawa, Y., Ishimaru, Y., Sei, H., et al. (2013). Histamine from brain resident MAST cells promotes wakefulness and modulates behavioral states. PLoS ONE 8:e78434. doi: 10.1371 /journal.pone. 0078434

Claes, S. J. (2004). Corticotropin-releasing hormone (CRH) in psychiatry: from stress to psychopathology. Ann. Med. 36, 50-61. doi: $10.1080 / 07853890310017044$

Cohen, M., Meir, T., Klein, E., Volpin, G., Assaf, M., and Pollack, S. (2011). Cytokine levels as potential biomarkers for predicting the development of posttraumatic stress symptoms in casualties of accidents. Int. J. Psychiatry Med. 42, 117-131. doi: 10.2190/PM.42.2.b

Collins-Praino, L. E., and Corrigan, F. (2017). Does neuroinflammation drive the relationship between tau hyperphosphorylation and dementia development following traumatic brain injury? Brain Behav. Immun. 60, 369-382. doi: 10.1016/j.bbi.2016.09.027

Colombo, E., and Farina, C. (2016). Astrocytes: key regulators of neuroinflammation. Trends Immunol. 37, 608-620. doi: 10.1016/j.it.2016. 06.006

Corrigan, F., Mander, K. A., Leonard, A. V., and Vink, R. (2016). Neurogenic inflammation after traumatic brain injury and its potentiation of classical inflammation. J. Neuroinflamm. 13:264. doi: 10.1186/s12974-016-0738-9

Crane, P. K., Gibbons, L. E., Dams-O'connor, K., Trittschuh, E., Leverenz, J. B. Keene, C. D., et al. (2016). Association of traumatic brain injury with late-life neurodegenerative conditions and neuropathologic findings. JAMA Neurol. 73, 1062-1069. doi: 10.1001/jamaneurol.2016.1948

Dams-O'connor, K., Guetta, G., Hahn-Ketter, A. E., and Fedor, A. (2016). Traumatic brain injury as a risk factor for Alzheimer's disease: current knowledge and future directions. Neurodegener. Dis. Manage. 6, 417-429. doi: $10.2217 / \mathrm{nmt}-2016-0017$

Dantzer, R., and Kelley, K. W. (2007). Twenty years of research on cytokine-induced sickness behavior. Brain Behav. Immun. 21, 153-160. doi: 10.1016/j.bbi.2006.09.006

De Berardis, D., Campanella, D., Gambi, F., La Rovere, R., Carano, A., Conti, C. M., et al. (2006). The role of C-reactive protein in mood disorders. Int. J. Immunopathol. Pharmacol. 19, 721-725. doi: 10.1177/039463200601900402

De Kloet, C. S., Vermetten, E., Geuze, E., Lentjes, E. G., Heijnen, C. J., Stalla, G. K., et al. (2008). Elevated plasma corticotrophin-releasing hormone levels in veterans with posttraumatic stress disorder. Prog. Brain Res. 167, 287-291. doi: 10.1016/S0079-6123(07)67025-3

Delpech, J. C., Madore, C., Nadjar, A., Joffre, C., Wohleb, E. S., and Laye, S. (2015). Microglia in neuronal plasticity: influence of stress. Neuropharmacology 96, 19-28. doi: 10.1016/j.neuropharm.2014.12.034

De Simone, R., Ajmone-Cat, M. A., Pandolfi, M., Bernardo, A., De Nuccio, C., Minghetti, L., et al. (2015). The mitochondrial uncoupling protein-2 is a master regulator of both M1 and M2 microglial responses. J. Neurochem. 135, 147-156. doi: 10.1111/jnc. 13244

Devoto, C., Arcurio, L., Fetta, J., Ley, M., Rodney, T., Kanefsky, R., et al. (2016). Inflammation relates to chronic behavioral and neurological symptoms in military with traumatic brain injuries. Cell Transplant. 26, 1169-1177. doi: 10.1177/0963689717714098

Digangi, J. A., Gomez, D., Mendoza, L., Jason, L. A., Keys, C. B., and Koenen, K. C. (2013). Pretrauma risk factors for posttraumatic stress disorder: a systematic review of the literature. Clin. Psychol. Rev. 33, 728-744. doi: $10.1016 /$ j.cpr.2013.05.002 
Domingues, C., Da Cruz, E. S. O. A., and Henriques, A. G. (2017). Impact of cytokines and chemokines on Alzheimer's disease neuropathological hallmarks. Curr. Alzheimer Res. 14, 870-882. doi: 10.2174/1567205014666170317113606

Dong, H., Zhang, W., Zeng, X., Hu, G., Zhang, H., He, S., et al. (2014a). Histamine induces upregulated expression of histamine receptors and increases release of inflammatory mediators from microglia. Mol. Neurobiol. 49, 1487-1500. doi: 10.1007/s12035-014-8697-6

Dong, H., Zhang, X., and Qian, Y. (2014b). Mast cells and neuroinflammation. Med. Sci. Monit. Basic Res. 20, 200-206. doi: 10.12659/MSMBR.893093

Dursa, E. K., Reinhard, M. J., Barth, S. K., and Schneiderman, A. I. (2014). Prevalence of a positive screen for PTSD among OEF/OIF and OEF/OIF-era veterans in a large population-based cohort. J. Trauma Stress 27, 542-549. doi: $10.1002 /$ jts. 21956

Eiland, L., and Romeo, R. D. (2013). Stress and the developing adolescent brain. Neuroscience 249, 162-171. doi: 10.1016/j.neuroscience.2012.10.048

Elder, G. A. (2015). Update on TBI and cognitive impairment in military veterans. Curr. Neurol. Neurosci. Rep. 15:68. doi: 10.1007/s11910-015-0591-8

Elder, G. A., Gama Sosa, M. A., De Gasperi, R., Stone, J. R., Dickstein, D. L., Haghighi, F., et al. (2015). Vascular and inflammatory factors in the pathophysiology of blast-induced brain injury. Front. Neurol. 6:48. doi: $10.3389 /$ fneur.2015.00048

Engebretsen, K. A., Johansen, J. D., Kezic, S., Linneberg, A., and Thyssen, J. P. (2016). The effect of environmental humidity and temperature on skin barrier function and dermatitis. J. Eur. Acad. Dermatol. Venereol. 30, 223-249. doi: $10.1111 /$ jdv. 13301

Esposito, P., Basu, S., Letourneau, R., Jacobson, S., and Theoharides, T. C. (2003). Corticotropin-releasing factor (CRF) can directly affect brain microvessel endothelial cells. Brain Res. 968, 192-198. doi: 10.1016/S0006-8993(03) 02237-6

Esposito, P., Gheorghe, D., Kandere, K., Pang, X., Connolly, R., Jacobson, S., et al. (2001). Acute stress increases permeability of the blood-brainbarrier through activation of brain mast cells. Brain Res. 888, 117-127. doi: 10.1016/S0006-8993(00)03026-2

Finch, C. E., and Morgan, T. E. (2007). Systemic inflammation, infection, ApoE alleles, and Alzheimer disease: a position paper. Curr. Alzheimer Res. 4, 185-189. doi: 10.2174/156720507780362254

Finnell, J. E., and Wood, S. K. (2016). Neuroinflammation at the interface of depression and cardiovascular disease: evidence from rodent models of social stress. Neurobiol. Stress 4, 1-14. doi: 10.1016/j.ynstr.2016.04.001

Flatt, J. D., Gilsanz, P., Quesenberry, C. P. Jr., Albers, K. B., and Whitmer, R. A. (2017). Post-traumatic stress disorder and risk of dementia among members of a health care delivery system. Alzheimers Dement. doi: 10.1016/j.jalz.2017.04.014. [Epub ahead of print].

Forsythe, P., and Ennis, M. (2000). Clinical consequences of mast cell heterogeneity. Inflamm. Res. 49, 147-154. doi: 10.1007/s000110050574

Frieri, M., Kumar, K., and Boutin, A. (2015). Role of mast cells in trauma and neuroinflammation in allergy immunology. Ann. Allergy Asthma Immunol. 115, 172-177. doi: 10.1016/j.anai.2015.06.025

Fu, A. K., Hung, K. W., Yuen, M. Y., Zhou, X., Mak, D. S., Chan, I. C., et al. (2016). IL-33 ameliorates Alzheimer's disease-like pathology and cognitive decline. Proc. Natl. Acad. Sci. U.S.A. 113, E2705-E2713. doi: 10.1073/pnas.1604032113

Galecki, P., Mossakowska-Wojcik, J., and Talarowska, M. (2018). The anti-inflammatory mechanism of antidepressants - SSRIs, SNRIs. Prog. Neuropsychopharmacol. Biol. Psychiatry 80, 291-294. doi: 10.1016/j.pnpbp.2017.03.016

Galli, S. J. (1990). New insights into "the riddle of the mast cells": microenvironmental regulation of mast cell development and phenotypic heterogeneity. Lab. Invest. 62, 5-33. doi: 10.1007/978-1-4612-0485-5_5

Galli, S. J. (2017). Mast cells and KIT as potential therapeutic targets in severe asthma. N. Engl. J. Med. 376, 1983-1984. doi: 10.1056/NEJMe1702653

Galli, S. J., and Gaudenzio, N. (2017). Human mast cells as antigen-presenting cells: when is this role important in vivo? J. Allergy Clin. Immunol. doi: 10.1016/j.jaci.2017.05.029. [Epub ahead of print].

Galli, S. J., and Tsai, M. (2012). IgE and mast cells in allergic disease. Nat. Med. 18, 693-704. doi: $10.1038 / \mathrm{nm} .2755$

Gangemi, S., Minciullo, P. L., Magliacane, D., Saitta, S., Loffredo, S., Saija, A., et al. (2015). Oxidative stress markers are increased in patients with mastocytosis. Allergy 70, 436-442. doi: 10.1111/all.12571
Gaudenzio, N., Sibilano, R., Marichal, T., Starkl, P., Reber, L. L., Cenac, N., et al. (2016). Different activation signals induce distinct mast cell degranulation strategies. J. Clin. Invest. 126, 3981-3998. doi: 10.1172/JCI85538

Georgin-Lavialle, S., Moura, D. S., Salvador, A., Chauvet-Gelinier, J. C., Launay, J. M., Damaj, G., et al. (2016). Mast cells' involvement in inflammation pathways linked to depression: evidence in mastocytosis. Mol. Psychiatry 21, 1511-1516. doi: 10.1038/mp.2015.216

Gilfillan, A. M., Austin, S. J., and Metcalfe, D. D. (2011). Mast cell biology: introduction and overview. Adv. Exp. Med. Biol. 716, 2-12. doi: 10.1007/978-1-4419-9533-9_1

Glass, C. K., Saijo, K., Winner, B., Marchetto, M. C., and Gage, F. H. (2010). Mechanisms underlying inflammation in neurodegeneration. Cell 140, 918-934. doi: 10.1016/j.cell.2010.02.016

Graziottin, A., Skaper, S. D., and Fusco, M. (2014). Mast cells in chronic inflammation, pelvic pain and depression in women. Gynecol. Endocrinol. 30, 472-477. doi: 10.3109/09513590.2014.911280

Groer, M. W., Kane, B., Williams, S. N., and Duffy, A. (2015). Relationship of PTSD symptoms with combat exposure, stress, and inflammation in American soldiers. Biol. Res. Nurs. 17, 303-310. doi: 10.1177/1099800414544949

Gruber, B. L., Marchese, M. J., and Kew, R. (1995). Angiogenic factors stimulate mast-cell migration. Blood 86, 2488-2493.

Gupta, R., and Sen, N. (2016). Traumatic brain injury: a risk factor for neurodegenerative diseases. Rev. Neurosci. 27, 93-100. doi: 10.1515/revneuro-2015-0017

Gurish, M. F., and Austen, K. F. (2001). The diverse roles of mast cells. J. Exp. Med. 194, F1-F5. doi: 10.1084/jem.194.1.F1

Harcha, P. A., Vargas, A., Yi, C., Koulakoff, A. A., Giaume, C., and Saez, J. C. (2015) Hemichannels are required for amyloid beta-peptide-induced degranulation and are activated in brain mast cells of APPswe/PS1dE9 mice. J. Neurosci. 35, 9526-9538. doi: 10.1523/JNEUROSCI.3686-14.2015

Hashioka, S., Mcgeer, P. L., Monji, A., and Kanba, S. (2009). Antiinflammatory effects of antidepressants: possibilities for preventives against Alzheimer's disease. Cent. Nerv. Syst. Agents Med. Chem. 9, 12-19. doi: $10.2174 / 187152409787601897$

Hayley, S. (2011). Toward an anti-inflammatory strategy for depression. Front. Behav. Neurosci. 5:19. doi: 10.3389/fnbeh.2011.00019

Hendriksen, E., Van Bergeijk, D., Oosting, R. S., and Redegeld, F. A. (2017). Mast cells in neuroinflammation and brain disorders. Neurosci. Biobehav. Rev. 79, 119-133. doi: 10.1016/j.neubiorev.2017.05.001

Heneka, M. T., Carson, M. J., El Khoury, J., Landreth, G. E., Brosseron, F., Feinstein, D. L., et al. (2015). Neuroinflammation in Alzheimer's disease. Lancet Neurol. 14, 388-405. doi: 10.1016/S1474-4422(15)70016-5

Hoeijmakers, L., Ruigrok, S. R., Amelianchik, A., Ivan, D., Van Dam, A. M., Lucassen, P. J., et al. (2017). Early-life stress lastingly alters the neuroinflammatory response to amyloid pathology in an Alzheimer's disease mouse model. Brain Behav. Immun. 63, 160-175. doi: 10.1016/j.bbi.2016.12.023

Hong, J. T. (2017). NF-kB as a mediator of brain inflammation in AD. CNS Neurol. Disord. Drug Targets doi: 10.2174/1871527316666170807130011. [Epub ahead of print].

Hudson, C. A., Christophi, G. P., Gruber, R. C., Wilmore, J. R., Lawrence, D. A., and Massa, P. T. (2008). Induction of IL-33 expression and activity in central nervous system glia. J. Leukoc. Biol. 84, 631-643. doi: 10.1189/jlb.1207830

Irani, A. M., and Schwartz, L. B. (1994). Human mast cell heterogeneity. Allergy Proc. 15, 303-308. doi: 10.2500/108854194778816472

Jin, Y., Silverman, A. J., and Vannucci, S. J. (2007). Mast cell stabilization limits hypoxic-ischemic brain damage in the immature rat. Dev. Neurosci. 29, 373-384. doi: 10.1159/000105478

Johnson, V. E., Stewart, W., and Smith, D. H. (2012). Widespread tau and amyloidbeta pathology many years after a single traumatic brain injury in humans. Brain Pathol. 22, 142-149. doi: 10.1111/j.1750-3639.2011.00513.x

Justice, N. J., Huang, L., Tian, J. B., Cole, A., Pruski, M., Hunt, A. J. Jr., et al. (2015). Posttraumatic stress disorder-like induction elevates beta-amyloid levels, which directly activates corticotropin-releasing factor neurons to exacerbate stress responses. J. Neurosci. 35, 2612-2623. doi: 10.1523/JNEUROSCI.3333-14.2015

Kalesnikoff, J., and Galli, S. J. (2008). New developments in mast cell biology. Nat. Immunol. 9, 1215-1223. doi: 10.1038/ni.f.216

Kandere-Grzybowska, K., Gheorghe, D., Priller, J., Esposito, P., Huang, M., Gerard, N., et al. (2003a). Stress-induced dura vascular permeability does not develop 
in mast cell-deficient and neurokinin-1 receptor knockout mice. Brain Res. 980, 213-220. doi: 10.1016/S0006-8993(03)02975-5

Kandere-Grzybowska, K., Kempuraj, D., Cao, J., Cetrulo, C. L., and Theoharides, T. C. (2006). Regulation of IL-1-induced selective IL-6 release from human mast cells and inhibition by quercetin. Br. J. Pharmacol. 148, 208-215. doi: 10.1038/sj.bjp.0706695

Kandere-Grzybowska, K., Letourneau, R., Kempuraj, D., Donelan, J., Poplawski, S., Boucher, W., et al. (2003b). IL-1 induces vesicular secretion of IL-6 without degranulation from human mast cells. J. Immunol. 171, 4830-4836. doi: 10.4049/jimmunol.171.9.4830

Karagkouni, A., Alevizos, M., and Theoharides, T. C. (2013). Effect of stress on brain inflammation and multiple sclerosis. Autoimmun. Rev. 12, 947-953. doi: 10.1016/j.autrev.2013.02.006

Kato, T. A., Hayakawa, K., Monji, A., and Kanba, S. (2013). Missing and possible link between neuroendocrine factors, neuropsychiatric disorders, and microglia. Front. Integr. Neurosci. 7:53. doi: 10.3389/fnint.2013.00053

Kempuraj, D., Madhappan, B., Christodoulou, S., Boucher, W., Cao, J., Papadopoulou, N., et al. (2005). Flavonols inhibit proinflammatory mediator release, intracellular calcium ion levels and protein kinase C theta phosphorylation in human mast cells. Br. J. Pharmacol. 145, 934-944. doi: 10.1038/sj.bjp.0706246

Kempuraj, D., Papadopoulou, N. G., Lytinas, M., Huang, M., KandereGrzybowska, K., Madhappan, B., et al. (2004). Corticotropin-releasing hormone and its structurally related urocortin are synthesized and secreted by human mast cells. Endocrinology 145, 43-48. doi: 10.1210/en.2003-0805

Kempuraj, D., Selvakumar, G. P., Zaheer, S., Thangavel, R., Ahmed, M. E., Raikwar, S., et al. (2017a). Cross-talk between glia, neurons and mast cells in neuroinflammation associated with Parkinson's disease. J. Neuroimmune Pharmacol. doi: 10.1007/s11481-017-9766-1. [Epub ahead of print].

Kempuraj, D., Thangavel, R., Fattal, R., Pattani, S., Yang, E., Zaheer, S., et al. (2016a). Mast cells release chemokine CCL2 in response to Parkinsonian Toxin 1-Methyl-4-Phenyl-Pyridinium (MPP(+)). Neurochem. Res. 41, 1042-1049. doi: 10.1007/s11064-015-1790-z

Kempuraj, D., Thangavel, R., Natteru, P. A., Selvakumar, G. P., Saeed, D., Zahoor, H., et al. (2016b). Neuroinflammation induces neurodegeneration. J. Neurol. Neurosurg Spine 1:1003.

Kempuraj, D., Thangavel, R., Selvakumar, G. P., Zaheer, S., Ahmed, M. E., Raikwar, S. P., et al. (2017b). Brain and peripheral atypical inflammatory mediators potentiate neuroinflammation and neurodegeneration. Front. Cell. Neurosci. 11:216. doi: 10.3389/fncel.2017.00216

Kempuraj, D., Thangavel, R., Yang, E., Pattani, S., Zaheer, S., Santillan, D. A., et al. (2015). Dopaminergic Toxin 1-Methyl-4-Phenylpyridinium, proteins alpha-synuclein and glia maturation factor activate mast cells and release inflammatory mediators. PLOS ONE 10:e0135776. doi: 10.1371/journal.pone. 0135776

Kim, D. Y., Hong, G. U., and Ro, J. Y. (2011). Signal pathways in astrocytes activated by cross-talk between of astrocytes and mast cells through CD40CD40L. J. Neuroinflamm. 8:25. doi: 10.1186/1742-2094-8-25

King, E., and Thomas, A. (2017). Systemic inflammation in lewy body diseases: a systematic review. Alzheimer Dis. Assoc. Disord. 31, 346-356. doi: 10.1097/WAD.0000000000000211

Kokiko-Cochran, O., Ransohoff, L., Veenstra, M., Lee, S., Saber, M., Sikora, M., et al. (2016). Altered neuroinflammation and behavior after traumatic brain injury in a mouse model of Alzheimer's disease. J. Neurotrauma 33, 625-640. doi: 10.1089/neu.2015.3970

Koran, M. E., Hohman, T. J., and Thornton-Wells, T. A. (2014). Genetic interactions found between calcium channel genes modulate amyloid load measured by positron emission tomography. Hum. Genet. 133, 85-93. doi: 10.1007/s00439-013-1354-8

Krause, K., Zuberbier, T., and Maurer, M. (2010). Modern approaches to the diagnosis and treatment of cold contact urticaria. Curr. Allergy Asthma Rep. 10, 243-249. doi: 10.1007/s11882-010-0121-3

Kritas, S. K., Caraffa, A., Antinolfi, P., Saggini, A., Pantalone, A., Rosati, M., et al. (2014a). Nerve growth factor interactions with mast cells. Int. J. Immunopathol. Pharmacol. 27, 15-19. doi: 10.1177/039463201402700103

Kritas, S. K., Saggini, A., Cerulli, G., Caraffa, A., Antinolfi, P., Pantalone, A., et al. (2014b). Corticotropin-releasing hormone, microglia and mental disorders. Int. J. Immunopathol. Pharmacol. 27, 163-167. doi: 10.1177/039463201402700203
Kritikou, E., Kuiper, J., Kovanen, P. T., and Bot, I. (2016). The impact of mast cells on cardiovascular diseases. Eur. J. Pharmacol. 778, 103-115. doi: 10.1016/j.ejphar.2015.04.050

Krystel-Whittemore, M., Dileepan, K. N., and Wood, J. G. (2015). Mast cell: a multi-functional master cell. Front. Immunol. 6:620. doi: $10.3389 /$ fimmu. 2015.00620

Kvetnoi, I. M., Kvetnaia, T. V., Riadnova, I., Fursov, B. B., Ernandes-Jago, H., and Blesa, J. R. (2003). [Expression of beta-amyloid and tau-protein in mastocytes in Alzheimer disease]. Arkh. Patol. 65, 36-39.

Lai, K. S. P., Liu, C. S., Rau, A., Lanctot, K. L., Kohler, C. A., Pakosh, M., et al. (2017). Peripheral inflammatory markers in Alzheimer's disease: a systematic review and meta-analysis of 175 studies. J. Neurol. Neurosurg. Psychiatry 88, 876-882. doi: 10.1136/jnnp-2017-316201

Lerman, I., Davis, B. A., Bertram, T. M., Proudfoot, J., Hauger, R. L., Coe, C. L., et al. (2016). Posttraumatic stress disorder influences the nociceptive and intrathecal cytokine response to a painful stimulus in combat veterans. Psychoneuroendocrinology 73, 99-108. doi: 10.1016/j.psyneuen.2016. 07.202

Levy, D., Edut, S., Baraz-Goldstein, R., Rubovitch, V., Defrin, R., Bree, D., et al. (2016). Responses of dural mast cells in concussive and blast models of mild traumatic brain injury in mice: potential implications for post-traumatic headache. Cephalalgia 36, 915-923. doi: 10.1177/0333102415617412

Li, N., Zhang, X., Dong, H., Hu, Y., and Qian, Y. (2017). Bidirectional relationship of mast cells-neurovascular unit communication in neuroinflammation and its involvement in POCD. Behav. Brain Res. 322, 60-69. doi: 10.1016/j.bbr.2017.01.006

Lim, R., Miller, J. F., and Zaheer, A. (1989). Purification and characterization of glia maturation factor beta: a growth regulator for neurons and glia. Proc. Natl. Acad. Sci. U.S.A. 86, 3901-3905. doi: 10.1073/pnas.86.10.3901

Lindqvist, D., Dhabhar, F. S., Mellon, S. H., Yehuda, R., Grenon, S. M., Flory, J. D., et al. (2017). Increased pro-inflammatory milieu in combat related PTSD - A new cohort replication study. Brain Behav. Immun. 59, 260-264. doi: 10.1016/j.bbi.2016.09.012

Lozada, A., Maegele, M., Stark, H., Neugebauer, E. M., and Panula, P. (2005). Traumatic brain injury results in mast cell increase and changes in regulation of central histamine receptors. Neuropathol. Appl. Neurobiol. 31, 150-162. doi: 10.1111/j.1365-2990.2004.00622.x

Lunderius-Andersson, C., Enoksson, M., and Nilsson, G. (2012). Mast cells respond to cell injury through the recognition of IL-33. Front. Immunol. 3:82. doi: 10.3389/fimmu.2012.00082

Lytinas, M., Kempuraj, D., Huang, M., Boucher, W., Esposito, P., and Theoharides, T. C. (2003). Acute stress results in skin corticotropin-releasing hormone secretion, mast cell activation and vascular permeability, an effect mimicked by intradermal corticotropin-releasing hormone and inhibited by histamine-1 receptor antagonists. Int. Arch. Allergy Immunol. 130, 224-231. doi: 10.1159/000069516

Machado, A., Herrera, A. J., De Pablos, R. M., Espinosa-Oliva, A. M., Sarmiento, M., Ayala, A., et al. (2014). Chronic stress as a risk factor for Alzheimer's disease. Rev. Neurosci. 25, 785-804. doi: 10.1515/revneuro-2014-0035

Martin, N. T., and Martin, M. U. (2016). Interleukin 33 is a guardian of barriers and a local alarmin. Nat. Immunol. 17, 122-131. doi: 10.1038/ni.3370

Maslinska, D., Laure-Kamionowska, M., Maslinski, K. T., Gujski, M., and Maslinski, S. (2007). Distribution of tryptase-containing mast cells and metallothionein reactive astrocytes in human brains with amyloid deposits. Inflamm. Res. 56(Suppl. 1), S17-S18. doi: 10.1007/s00011-006-0508-8

Mcgeer, E. G., and Mcgeer, P. L. (2010). Neuroinflammation in Alzheimer's disease and mild cognitive impairment: a field in its infancy. J. Alzheimers. Dis. 19, 355-361. doi: 10.3233/JAD-2010-1219

McGeer, P. L., and McGeer, E. G. (2015). Targeting microglia for the treatment of Alzheimer's disease. Expert Opin. Ther. Targets 19, 497-506. doi: $10.1517 / 14728222.2014 .988707$

McGeer, P. L., Rogers, J., and McGeer, E. G. (2016). Inflammation, antiinflammatory agents, and Alzheimer's disease: the last 22 years. $J$. Alzheimers Dis. 54, 853-857. doi: 10.3233/JAD-160488

McKittrick, C. M., Lawrence, C. E., and Carswell, H. V. (2015). Mast cells promote blood brain barrier breakdown and neutrophil infiltration in a mouse model of focal cerebral ischemia. J. Cereb. Blood Flow Metab. 35, 638-647. doi: $10.1038 /$ jcbfm. 2014.239 
Mcmanus, R. M., and Heneka, M. T. (2017). Role of neuroinflammation in neurodegeneration: new insights. Alzheimers Res. Ther. 9:14. doi: 10.1186/s13195-017-0241-2

Mendez, M. F. (2017). What is the Relationship of Traumatic Brain Injury to Dementia? J. Alzheimers Dis. 57, 667-681. doi: 10.3233/JAD-161002

Mendoza, C., Barreto, G. E., Avila-Rodriguez, M., and Echeverria, V. (2016). Role of neuroinflammation and sex hormones in war-related PTSD. Mol. Cell. Endocrinol. 434, 266-277. doi: 10.1016/j.mce.2016.05.016

Miller, K., Driscoll, D., Smith, L. M., and Ramaswamy, S. (2017). The role of inflammation in late-life post-traumatic stress disorder. Mil. Med. 182, e1815e1818. doi: 10.7205/MILMED-D-17-00073

Mohammadzadeh Honarvar, N., Saedisomeolia, A., Abdolahi, M., Shayeganrad, A., Taheri Sangsari, G., Hassanzadeh Rad, B., et al. (2017). Molecular anti-inflammatory mechanisms of retinoids and carotenoids in Alzheimer's disease: a review of current evidence. J. Mol. Neurosci. 61, 289-304. doi: 10.1007/s12031-016-0857-x

Mondelli, V., Vernon, A. C., Turkheimer, F., Dazzan, P., and Pariante, C. M. (2017). Brain microglia in psychiatric disorders. Lancet Psychiatry 4, 563-572. doi: 10.1016/S2215-0366(17)30101-3

Moretti, R., Chhor, V., Bettati, D., Banino, E., De Lucia, S., Le Charpentier, T., et al. (2016). Contribution of mast cells to injury mechanisms in a mouse model of pediatric traumatic brain injury. J. Neurosci. Res. 94, 1546-1560. doi: 10.1002/jnr.23911

Morgese, M. G., Schiavone, S., and Trabace, L. (2017). Emerging role of amyloid beta in stress response: implication for depression and diabetes. Eur. J. Pharmacol. 817, 22-29. doi: 10.1016/j.ejphar.2017.08.031

Muhie, S., Gautam, A., Chakraborty, N., Hoke, A., Meyerhoff, J., Hammamieh, R., et al. (2017). Molecular indicators of stress-induced neuroinflammation in a mouse model simulating features of post-traumatic stress disorder. Transl. Psychiatry 7:e1135. doi: 10.1038/tp.2017.91

Mukai, K., Tsai, M., Starkl, P., Marichal, T., and Galli, S. J. (2016). IgE and mast cells in host defense against parasites and venoms. Semin. Immunopathol. 38, 581-603. doi: 10.1007/s00281-016-0565-1

Nakae, S., Suto, H., Iikura, M., Kakurai, M., Sedgwick, J. D., Tsai, M., et al. (2006). Mast cells enhance $\mathrm{T}$ cell activation: importance of mast cell costimulatory molecules and secreted TNF. J. Immunol. 176, 2238-2248. doi: 10.4049/jimmunol.176.4.2238

Nakamura, Y., Ishimaru, K., Shibata, S., and Nakao, A. (2017). Regulation of plasma histamine levels by the mast cell clock and its modulation by stress. Sci. Rep. 7:39934. doi: 10.1038/srep39934

Nautiyal, K. M., Ribeiro, A. C., Pfaff, D. W., and Silver, R. (2008). Brain mast cells link the immune system to anxiety-like behavior. Proc. Natl. Acad. Sci. U.S.A. 105, 18053-18057. doi: 10.1073/pnas.0809479105

Nelson, R. B., Siman, R., Iqbal, M. A., and Potter, H. (1993). Identification of a chymotrypsin-like mast cell protease in rat brain capable of generating the $\mathrm{N}$ terminus of the Alzheimer amyloid beta-protein. J. Neurochem. 61, 567-577. doi: 10.1111/j.1471-4159.1993.tb02160.x

Nezi, M., Mastorakos, G., and Mouslech, Z. (2000). "Corticotropin releasing hormone and the immune/inflammatory response," in Endotext, eds L. J. De Groot, G. Chrousos, K. Dungan, K. R. Feingold, A. Grossman, J. M. Hershman, C. Koch, M. Korbonits, R. Mclachlan, M. New, J. Purnell, R. Rebar, F. Singer, and A. Vinik (South Dartmouth, MA: MDText.com, Inc).

Niederhoffer, N., Levy, R., Sick, E., Andre, P., Coupin, G., Lombard, Y., et al. (2009). Amyloid beta peptides trigger CD47-dependent mast cell secretory and phagocytic responses. Int. J. Immunopathol. Pharmacol. 22, 473-483. doi: $10.1177 / 039463200902200224$

Niraula, A., Sheridan, J. F., and Godbout, J. P. (2016). Microglia priming with aging and stress. Neuropsychopharmacology 42, 318-333. doi: 10.1038/npp.2016.185

Nozu, T., Miyagishi, S., Nozu, R., Takakusaki, K., and Okumura, T. (2017). Repeated water avoidance stress induces visceral hypersensitivity; role of IL1, IL-6 and peripheral corticotropin-releasing factor. J. Gastroenterol. Hepatol. 32, 1958-1965. doi: 10.1111/jgh.13787

O’bryant, S. E., Lista, S., Rissman, R. A., Edwards, M., Zhang, F., Hall, J., et al. (2016). Comparing biological markers of Alzheimer's disease across blood fraction and platforms: comparing apples to oranges. Alzheimers Dement. 3, 27-34. doi: 10.1016/j.dadm.2015.12.003

O'donovan, A., Cohen, B. E., Seal, K. H., Bertenthal, D., Margaretten, M., Nishimi, K., et al. (2015). Elevated risk for autoimmune disorders in iraq and afghanistan veterans with posttraumatic stress disorder. Biol. Psychiatry 77, 365-374 doi: 10.1016/j.biopsych.2014.06.015

Papadopoulou, N. G., Oleson, L., Kempuraj, D., Donelan, J., Cetrulo, C. L., and Theoharides, T. C. (2005). Regulation of corticotropin-releasing hormone receptor-2 expression in human cord blood-derived cultured mast cells. J. Mol. Endocrinol. 35, R1-R8. doi: 10.1677/jme.1.01833

Pardon, M. C. (2011). Therapeutic potential of some stress mediators in early Alzheimer's disease. Exp. Gerontol. 46, 170-173. doi: 10.1016/j.exger.2010.09.006

Passos, I. C., Vasconcelos-Moreno, M. P., Costa, L. G., Kunz, M., Brietzke, E., Quevedo, J., et al. (2015). Inflammatory markers in post-traumatic stress disorder: a systematic review, meta-analysis, and meta-regression. Lancet Psychiatry 2, 1002-1012. doi: 10.1016/S2215-0366(15)00309-0

Pedersen, W. A., Mccullers, D., Culmsee, C., Haughey, N. J., Herman, J. P., and Mattson, M. P. (2001). Corticotropin-releasing hormone protects neurons against insults relevant to the pathogenesis of Alzheimer's disease. Neurobiol. Dis. 8, 492-503. doi: 10.1006/nbdi.2001.0395

Perry, V. H. (2016). Microglia. Microbiol. Spectr. 4. doi: 10.1128/microbiolspec.MCHD-0003-2015

Perry, V. H., and Holmes, C. (2014). Microglial priming in neurodegenerative disease. Nat. Rev. Neurol. 10, 217-224. doi: 10.1038/nrneurol.2014.38

Perry, V. H., Nicoll, J. A., and Holmes, C. (2010). Microglia in neurodegenerative disease. Nat. Rev. Neurol. 6, 193-201. doi: 10.1038/nrneurol.2010.17

Pervanidou, P., and Chrousos, G. P. (2012). Posttraumatic stress disorder in children and adolescents: neuroendocrine perspectives. Sci. Signal. 5:pt6. doi: 10.1126/scisignal.2003327

Petra, A. I., Panagiotidou, S., Stewart, J. M., Conti, P., and Theoharides, T. C. (2014). Spectrum of mast cell activation disorders. Expert Rev. Clin. Immunol. 10, 729-739. doi: 10.1586/1744666X.2014.906302

Piirainen, S., Youssef, A., Song, C., Kalueff, A. V., Landreth, G. E., Malm, T., et al. (2017). Psychosocial stress on neuroinflammation and cognitive dysfunctions in Alzheimer's disease: the emerging role for microglia? Neurosci. Biobehav. Rev. 77, 148-164. doi: 10.1016/j.neubiorev.2017.01.046

Powers, A., Michopoulos, V., Conneely, K., Gluck, R., Dixon, H., Wilson, J., et al. (2016). Emotion dysregulation and inflammation in African-American women with type 2 diabetes. Neural Plast. 2016:8926840. doi: 10.1155/2016/8926840

Purcell, W. M., and Atterwill, C. K. (1995). Mast cells in neuroimmune function: neurotoxicological and neuropharmacological perspectives. Neurochem. Res. 20, 521-532. doi: 10.1007/BF01694534

Purcell, W. M., Westgate, C., and Atterwill, C. K. (1996). Rat brain mast cells: an in vitro paradigm for assessing the toxic effects of neurotropic therapeutics. Neurotoxicology $17,845-850$.

Qu, T. T., Deng, J. X., Li, R. L., Cui, Z. J., Wang, X. Q., Wang, L., et al. (2017). Stress injuries and autophagy in mouse hippocampus after chronic cold exposure. Neural. Regen. Res. 12, 440-446. doi: 10.4103/1673-5374.202932

Rehman, H. U. (2002). Role of CRH in the pathogenesis of dementia of Alzheimer's type and other dementias. Curr. Opin. Investig. Drugs 3, 1637-1642.

Ribatti, D. (2015). The crucial role of mast cells in blood-brain barrier alterations. Exp. Cell Res. 338, 119-125. doi: 10.1016/j.yexcr.2015.05.013

Rothwell, N. J., and Luheshi, G. N. (2000). Interleukin 1 in the brain: biology, pathology and therapeutic target. Trends Neurosci. 23, 618-625. doi: 10.1016/S0166-2236(00)01661-1

Rothwell, N. J., and Strijbos, P. J. (1995). Cytokines in neurodegeneration and repair. Int. J. Dev. Neurosci. 13, 179-185. doi: 10.1016/0736-5748(95)00018-C

Rozniecki, J. J., Sahagian, G. G., Kempuraj, D., Tao, K., Jocobson, S., Zhang, B., et al. (2010). Brain metastases of mouse mammary adenocarcinoma is increased by acute stress. Brain Res. 1366, 204-210. doi: 10.1016/j.brainres.2010. 09.085

Sant, G. R., Kempuraj, D., Marchand, J. E., and Theoharides, T. C. (2007). The mast cell in interstitial cystitis: role in pathophysiology and pathogenesis. Urology 69, 34-40. doi: 10.1016/j.urology.2006.08.1109

Sawikr, Y., Yarla, N. S., Peluso, I., Kamal, M. A., Aliev, G., and Bishayee, A. (2017). Neuroinflammation in Alzheimer's disease: the preventive and therapeutic potential of polyphenolic nutraceuticals. Adv. Protein Chem. Struct. Biol. 108, 33-57. doi: 10.1016/bs.apcsb.2017.02.001

Sayed, B. A., Walker, M. E., and Brown, M. A. (2011). Cutting edge: mast cells regulate disease severity in a relapsing-remitting model of multiple sclerosis. J. Immunol. 186, 3294-3298. doi: 10.4049/jimmunol.1003574 
Schain, M., and Kreisl, W. C. (2017). Neuroinflammation in neurodegenerative disorders-a review. Curr. Neurol. Neurosci. Rep. 17:25. doi: 10.1007/s11910-017-0733-2

Setiawan, E., Wilson, A. A., Mizrahi, R., Rusjan, P. M., Miler, L., Rajkowska, G., et al. (2015). Role of translocator protein density, a marker of neuroinflammation, in the brain during major depressive episodes. JAMA Psychiatry 72, 268-275. doi: 10.1001/jamapsychiatry.2014.2427

Shaik-Dasthagirisaheb, Y. B., and Conti, P. (2016). The role of mast cells in Alzheimer's disease. Adv. Clin. Exp. Med. 25, 781-787. doi: $10.17219 /$ acem/61914

Shishido, H., Kishimoto, Y., Kawai, N., Toyota, Y., Ueno, M., Kubota, T., et al. (2016). Traumatic brain injury accelerates amyloid-beta deposition and impairs spatial learning in the triple-transgenic mouse model of Alzheimer's disease. Neurosci. Lett. 629, 62-67. doi: 10.1016/j.neulet.2016.06.066

Skaper, S. D. (2016). Mast cell - glia dialogue in chronic pain and neuropathic pain: blood-brain barrier implications. CNS Neurol. Disord. Drug Targets 15, 1072-1078. doi: 10.2174/1871527315666160829105533

Skaper, S. D., Facci, L., and Giusti, P. (2014). Neuroinflammation, microglia and mast cells in the pathophysiology of neurocognitive disorders: a review. CNS Neurol. Disord. Drug Targets 13, 1654-1666. doi: 10.2174/1871527313666141130224206

Skaper, S. D., Giusti, P., and Facci, L. (2012). Microglia and mast cells: two tracks on the road to neuroinflammation. FASEB J. 26, 3103-3117. doi: 10.1096/fj.11-197194

Solomon, Z., Levin, Y., Assayag, E. B., Furman, O., Shenhar-Tsarfaty, S., Berliner, S., et al. (2017). The implication of combat stress and PTSD trajectories in metabolic syndrome and elevated C-Reactive protein levels: a longitudinal study. J. Clin. Psychiatry. doi: 10.4088/JCP.16m11344. [Epub ahead of print].

Spangenberg, E. E., and Green, K. N. (2017). Inflammation in Alzheimer's disease: lessons learned from microglia-depletion models. Brain Behav. Immun. 61, 1-11. doi: 10.1016/j.bbi.2016.07.003

Stolmeier, D., Thangavel, R., Anantharam, P., Khan, M. M., Kempuraj, D., and Zaheer, A. (2013). Glia maturation factor expression in hippocampus of human Alzheimer's disease. Neurochem. Res. 38, 1580-1589. doi: 10.1007/s11064-013-1059-3

Strbian, D., Karjalainen-Lindsberg, M. L., Kovanen, P. T., Tatlisumak, T., and Lindsberg, P. J. (2007). Mast cell stabilization reduces hemorrhage formation and mortality after administration of thrombolytics in experimental ischemic stroke. Circulation 116, 411-418. doi: 10.1161/CIRCULATIONAHA.106.655423

Strbian, D., Kovanen, P. T., Karjalainen-Lindsberg, M. L., Tatlisumak, T., and Lindsberg, P. J. (2009). An emerging role of mast cells in cerebral ischemia and hemorrhage. Ann. Med. 41, 438-450. doi: 10.1080/07853890902887303

Suurmond, J., Van Der Velden, D., Kuiper, J., Bot, I., and Toes, R. E. (2016). Mast cells in rheumatic disease. Eur. J. Pharmacol. 778, 116-124. doi: 10.1016/j.ejphar.2015.03.085

Tagen, M., Elorza, A., Kempuraj, D., Boucher, W., Kepley, C. L., Shirihai, O. S., et al. (2009). Mitochondrial uncoupling protein 2 inhibits mast cell activation and reduces histamine content. J. Immunol. 183, 6313-6319. doi: $10.4049 /$ jimmunol.0803422

Thangavel, R., Kempuraj, D., Stolmeier, D., Anantharam, P., Khan, M., and Zaheer, A. (2013). Glia maturation factor expression in entorhinal cortex of Alzheimer's disease brain. Neurochem. Res. 38, 1777-1784. doi: 10.1007/s11064-0131080-6

Thangavel, R., Kempuraj, D., Zaheer, S., Raikwar, S., Ahmed, M. E., Selvakumar, G. P., et al. (2017). Glia maturation factor and mitochondrial uncoupling proteins 2 and 4 expression in the temporal cortex of Alzheimer's disease brain. Front. Aging Neurosci. 9:150. doi: 10.3389/fnagi.2017.00150

Theoharides, T. C. (2017). Neuroendocrinology of mast cells: challenges and controversies. Exp. Dermatol. 26, 751-759. doi: 10.1111/exd.13288

Theoharides, T. C., Alysandratos, K. D., Angelidou, A., Delivanis, D. A., Sismanopoulos, N., Zhang, B., et al. (2012a). Mast cells and inflammation. Biochim. Biophys. Acta 1822, 21-33. doi: 10.1016/j.bbadis.2010.12.014

Theoharides, T. C., Asadi, S., and Patel, A. B. (2013). Focal brain inflammation and autism. J. Neuroinflamm. 10:46. doi: 10.1186/1742-2094-10-46

Theoharides, T. C., Donelan, J., Kandere-Grzybowska, K., and Konstantinidou, A. (2005). The role of mast cells in migraine pathophysiology. Brain Res. Brain Res. Rev. 49, 65-76. doi: 10.1016/j.brainresrev.2004.11.006
Theoharides, T. C., Donelan, J. M., Papadopoulou, N., Cao, J., Kempuraj, D., and Conti, P. (2004). Mast cells as targets of corticotropin-releasing factor and related peptides. Trends Pharmacol. Sci. 25, 563-568. doi: $10.1016 /$ j.tips.2004.09.007

Theoharides, T. C., Enakuaa, S., Sismanopoulos, N., Asadi, S., Papadimas, E. C., Angelidou, A., et al. (2012b). Contribution of stress to asthma worsening through mast cell activation. Ann. Allergy Asthma Immunol. 109, 14-19. doi: $10.1016 /$ j.anai.2012.03.003

Theoharides, T. C., and Konstantinidou, A. D. (2007). Corticotropin-releasing hormone and the blood-brain-barrier. Front. Biosci. 12, 1615-1628. doi: $10.2741 / 2174$

Theoharides, T. C., Rozniecki, J. J., Sahagian, G., Jocobson, S., Kempuraj, D., Conti, P., et al. (2008). Impact of stress and mast cells on brain metastases. J. Neuroimmunol. 205, 1-7. doi: 10.1016/j.jneuroim.2008.09.014

Theoharides, T. C., Spanos, C., Pang, X., Alferes, L., Ligris, K., Letourneau, R., et al. (1995). Stress-induced intracranial mast cell degranulation: a corticotropin-releasing hormone-mediated effect. Endocrinology 136, 5745-5750. doi: 10.1210/endo.136.12.7588332

Theoharides, T. C., Stewart, J. M., Panagiotidou, S., and Melamed, I. (2016). Mast cells, brain inflammation and autism. Eur. J. Pharmacol. 778, 96-102. doi: 10.1016/j.ejphar.2015.03.086

Theoharides, T. C., Zhang, B., Kempuraj, D., Tagen, M., Vasiadi, M., Angelidou, A., et al. (2010). IL-33 augments substance P-induced VEGF secretion from human mast cells and is increased in psoriatic skin. Proc. Natl. Acad. Sci. U.S.A. 107, 4448-4453. doi: 10.1073/pnas.1000803107

Tsai, M., Grimbaldeston, M., and Galli, S. J. (2011). Mast cells and immunoregulation/immunomodulation. Adv. Exp. Med. Biol. 716, 186-211. doi: 10.1007/978-1-4419-9533-9_11

Tweedie, D., Rachmany, L., Rubovitch, V., Li, Y., Holloway, H. W., Lehrmann, E., et al. (2016). Blast traumatic brain injury-induced cognitive deficits are attenuated by preinjury or postinjury treatment with the glucagonlike peptide-1 receptor agonist, exendin-4. Alzheimers Dement. 12, 34-48. doi: $10.1016 /$ j.jalz.2015.07.489

Vink, R., Young, A., Bennett, C. J., Hu, X., Connor, C. O., Cernak, I., et al. (2003). Neuropeptide release influences brain edema formation after diffuse traumatic brain injury. Acta Neurochir. Suppl. 86, 257-260. doi: 10.1007/978-3-7091-0651-8_55

Wang, R., Yin, X., Zhang, H., Wang, J., Chen, L., Chen, J., et al. (2016). Effects of a moderately lower temperature on the proliferation and degranulation of rat mast cells. J. Immunol. Res. 2016:8439594. doi: 10.1155/2016/8439594

Wang, Z., and Young, M. R. (2016). PTSD, a disorder with an immunological component. Front. Immunol. 7:219. doi: 10.3389/fimmu.2016.00219

Wernersson, S., and Pejler, G. (2014). Mast cell secretory granules: armed for battle. Nat. Rev. Immunol. 14, 478-494. doi: 10.1038/nri3690

Wohleb, E. S. (2016). Neuron-Microglia interactions in mental health disorders: "For Better, and For Worse". Front. Immunol. 7:544. doi: 10.3389/fimmu.2016.00544

Wolf, E. J., and Schnurr, P. P. (2016). PTSD-related cardiovascular disease and accelerated cellular aging. Psychiatr. Ann. 46, 527-532. doi: 10.3928/00485713-20160729-01

Xiong, Z., Thangavel, R., Kempuraj, D., Yang, E., Zaheer, S., and Zaheer, A. (2014). Alzheimer's disease: evidence for the expression of interleukin33 and its receptor ST2 in the brain. J. Alzheimers. Dis. 40, 297-308. doi: 10.3233/JAD-132081

Yasuoka, S., Kawanokuchi, J., Parajuli, B., Jin, S., Doi, Y., Noda, M., et al. (2011). Production and functions of IL-33 in the central nervous system. Brain Res. 1385, 8-17. doi: 10.1016/j.brainres.2011.02.045

Yehya, M., and Torbey, M. T. (2017). The role of mast cells in intracerebral hemorrhage. Neurocrit. Care. doi: 10.1007/s12028-017-0416-5. [Epub ahead of print].

Young, J. S., Hobbs, J. G., and Bailes, J. E. (2016). The impact of traumatic brain injury on the aging brain. Curr. Psychiatry Rep. 18:81. doi: 10.1007/s11920-016-0719-9

Yuan, H., Zhu, X., Zhou, S., Chen, Q., Zhu, X., Ma, X., et al. (2010). Role of mast cell activation in inducing microglial cells to release neurotrophin. J. Neurosci. Res. 88, 1348-1354. doi: 10.1002/jnr.22304

Zaheer, A., Sahu, S. K., Wu, Y., Zaheer, A., Haas, J., Lee, K., et al. (2007). Diminished cytokine and chemokine expression in the central nervous system 
of GMF-deficient mice with experimental autoimmune encephalomyelitis. Brain Res. 1144, 239-247. doi: 10.1016/j.brainres.2007.01.075

Zaheer, A., Zaheer, S., Thangavel, R., Wu, Y., Sahu, S. K., and Yang, B. (2008). Glia maturation factor modulates beta-amyloid-induced glial activation, inflammatory cytokine/chemokine production and neuronal damage. Brain Res. 1208, 192-203. doi: 10.1016/j.brainres.2008.02.093

Zaheer, S., Thangavel, R., Sahu, S. K., and Zaheer, A. (2011a). Augmented expression of glia maturation factor in Alzheimer's disease. Neuroscience 194, 227-233. doi: 10.1016/j.neuroscience.2011.07.069

Zaheer, S., Wu, Y., Sahu, S. K., and Zaheer, A. (2011b). Suppression of neuro inflammation in experimental autoimmune encephalomyelitis by glia maturation factor antibody. Brain Res. 1373, 230-239. doi: 10.1016/j.brainres.2010.12.003

Zarnegar, B., Mendez-Enriquez, E., Westin, A., Soderberg, C., Dahlin, J. S., Gronvik, K. O., et al. (2017). Influenza infection in mice induces accumulation of lung mast cells through the recruitment and maturation of mast cell progenitors. Front. Immunol. 8:310. doi: 10.3389/fimmu.2017. 00310

Zass, L. J., Hart, S. A., Seedat, S., Hemmings, S. M., and Malan-Muller, S. (2017). Neuroinflammatory genes associated with post-traumatic stress disorder: implications for comorbidity. Psychiatr. Genet. 27, 1-16. doi: 10.1097/YPG.0000000000000143

Zhang, C., and Rissman, R. A. (2017). Corticotropin-releasing factor receptor-1 modulates biomarkers of DNA oxidation in Alzheimer's disease mice. PLoS ONE 12:0181367. doi: 10.1371/journal.pone.0181367

Ziemka-Nalecz, M., Jaworska, J., and Zalewska, T. (2017). Insights into the neuroinflammatory responses after neonatal hypoxia-ischemia. J. Neuropathol. Exp. Neurol. 76, 644-654. doi: 10.1093/jnen/nlx046

Conflict of Interest Statement: The authors declare that the research was conducted in the absence of any commercial or financial relationships that could be construed as a potential conflict of interest.

Copyright (® 2017 Kempuraj, Selvakumar, Thangavel, Ahmed, Zaheer, Raikwar, Iyer, Bhagavan, Beladakere-Ramaswamy and Zaheer. This is an open-access article distributed under the terms of the Creative Commons Attribution License (CC BY). The use, distribution or reproduction in other forums is permitted, provided the original author(s) or licensor are credited and that the original publication in this journal is cited, in accordance with accepted academic practice. No use, distribution or reproduction is permitted which does not comply with these terms. 